Cite this: Dalton Trans., 2014, 43, 10725

\title{
Tuning coordination modes of pyridine/thioether Schiff base (NNS) ligands to mononuclear manganese carbonyls $\uparrow$
}

\author{
Simone E. A. Lumsden, Gummadi Durgaprasad, Keren A. Thomas Muthiah and \\ Michael J. Rose*
}

\begin{abstract}
We have investigated the coordination modes of NNS Schiff base, thioether ligands to manganese(।) carbonyls. The ligands contain ortho substituted pyridines $\left(\mathrm{H}, \mathrm{CH}_{3}, \mathrm{OCH}_{3}\right.$, fluorophenyl) and varying substituents $\left(\mathrm{H}, \mathrm{CH}_{3}\right)$ at the Schiff base linkage. In general, reaction of $\left[\mathrm{Mn}(\mathrm{CO})_{5} \mathrm{Br}\right]$ with a tridentate NNS ligand in $\mathrm{CH}_{2} \mathrm{Cl}_{2}$ affords species in which the thioether-S may be bound or unbound to the manganese center, depending on the steric and electronic substitution in the ligand framework; as a result, the complexes exhibit two or three carbonyl ligands, respectively. Aldehyde-derived ligand frames $\left({ }_{R 1} N_{H} N S\right)$ generally afford complexes of type $\left.\left[{ }_{R} N N S\right) M n(C O)_{3} \mathrm{Br}\right]\left(\mathbf{1}_{\mathrm{CO}}, \mathbf{2}_{\mathrm{CO}}, \mathbf{3}_{\mathrm{CO}} ; \mathrm{R}=\mathrm{H}, \mathrm{OCH}_{3}, \mathrm{CH}_{3}\right)$ that exhibit incomplete ligation of the chelate ( $\mathrm{S}$ not bound) in $\mathrm{X}$-ray structures. In contrast, use of the iminomethyl ligand ( $\left.\mathrm{N}_{\mathrm{Me}} \mathrm{NS}\right)$ affords a complex of formula $\left[\left(\mathrm{N}_{\mathrm{Me}} \mathrm{NS}\right) \mathrm{Mn}(\mathrm{CO})_{2} \mathrm{Br}\right]\left(\mathbf{4}_{\mathrm{Co}}\right)$, in which the mixed N/thioether-S stabilizes the $\left\{\mathrm{Mn}(\mathrm{CO})_{2}\right\}^{+}$fragment. In solid state IR spectra, complexes of type $\left[\left({ }_{R} N N S\right) M n(C O)_{3} \mathrm{Br}\right]$ $\left(\mathbf{1}_{\mathrm{CO}}\right.$ through $\left.\mathbf{3}_{\mathrm{CO}}\right)$ afford three $\nu(\mathrm{CO})$ in the range $\sim 2060-1865 \mathrm{~cm}^{-1}$; the dicarbonyl complex [(N $\mathrm{Ne}_{\mathrm{NS}}{ }$ $\mathrm{Mn}(\mathrm{CO})_{2} \mathrm{Br}$ ( $\left.4_{\mathrm{CO}}\right)$ exhibits two carbonyl stretches in the range $\sim 1920-1845 \mathrm{~cm}^{-1}$. Prolonged storage of the tricarbonyl [( $\left.\left.\mathrm{Me}_{\mathrm{NNS}}\right) \mathrm{Mn}(\mathrm{CO})_{3} \mathrm{Br}\right]\left(3_{\mathrm{CO}}\right)$ in presence of trace dioxygen affords the dibromide species $\left[\left({ }_{\mathrm{Me}} \mathrm{NNS}\right) \mathrm{Mn}(\mathrm{Br})_{2}\right]\left(\mathbf{3}_{\mathrm{Br}}\right)$, in which the thioether S reliably binds to the $\mathrm{Mn}(॥)$ center. Complexes $\mathbf{1}_{\mathrm{CO}}-\mathbf{3}_{\mathrm{CO}}$ exhibit simple, diamagnetic ${ }^{1} \mathrm{H}$ NMR spectra in $\mathrm{CD}_{2} \mathrm{Cl}_{2}$. The S-ligated complex $\mathbf{4}_{\mathrm{co}}$ exhibits spectra consistent with a mixture of an S-bound (6-coordinate) and S-unbound (5-coordinate) species as represented by $\left[\left(\mathrm{N}_{\mathrm{Me}} \mathrm{NS}\right) \mathrm{Mn}(\mathrm{CO})_{2} \mathrm{Br}\right] \leftrightarrow\left[\left(\mathrm{N}_{\mathrm{Me}} \mathrm{NS}\right) \mathrm{Mn}(\mathrm{CO})_{2} \mathrm{Br}\right]$. Lastly, we obtained crystal structures of the $\mathrm{S}$-bound and S-unbound conformers derived from the same ligand - the fluorophenyl derived $\mathrm{FPhNNS}_{\text {, }}$ namely $\left[\left(\mathrm{FPh}_{\mathrm{N}} \mathrm{NNS}\right) \mathrm{Mn}(\mathrm{CO})_{3} \mathrm{Br}\right]\left(\mathbf{5}_{\mathrm{CO}-\mathrm{a}}\right)$ and $\left[\left({ }_{\mathrm{FPh}} N N S\right) \mathrm{Mn}(\mathrm{CO})_{2} \mathrm{Br}\right]\left(\mathbf{5}_{\mathrm{CO}-\mathrm{b}}\right)$. This report represents several examples of a thioether-stabilized $\left\{\mathrm{Mn}(\mathrm{CO})_{2}\right\}^{+}$fragment, a deviation from the usual 'piano stool' $\mathrm{Mn}(\mathrm{I})$ tricarbonyl motif. We highlight that coordination of these NNS ligands to $\mathrm{Mn}(\mathrm{I})$ carbonyls occurs on a soft conformational landscape, and that ligand substituents can be rationally employed to favor the desired coordination mode.
\end{abstract}

Received 26th February 2014, Accepted 28th April 2014 DOI: $10.1039 / c 4 d t 00600 c$ www.rsc.org/dalton nyls have found use in carbon-carbon bond forming reactions, ${ }^{4}$ as well as the study of redox-active ligands. ${ }^{5}$ Organometallic species of manganese carbonyls have also been explored in catalytic hydrosilylations ${ }^{6}$ and alcoholysis of silanes. ${ }^{7}$ More recently, manganese carbonyls derived from bpy (2,2'-bipyridine) have been used in place of rhenium carbonyls in the electrocatalytic reduction of $\mathrm{CO}_{2}$ to $\mathrm{CO},{ }^{8}$ a promising direction for energy-related catalysis by earth abundant metals. ${ }^{9}$

In our research, we are interested in the fundamental coordination chemistry of multi-dentate ligands bearing nitrogen and sulfur donors to mononuclear metal carbonyls of the late first row. The low-spin, $\mathrm{d}^{6}$ configuration of $\mathrm{Mn}$ (I) carbonyls makes them amenable to isolation and solution studies. The

\footnotetext{
Department of Chemistry, The University of Texas at Austin, USA

E-mail:mrose@cm.utexas.edu

$\dagger$ Electronic supplementary information (ESI) available: CIF files for all X-ray structures; VT ${ }^{1} \mathrm{H}$ NMR spectrum of $\mathbf{1}_{\mathrm{CO}}$ (Fig. S1); disorder model for $\mathbf{5}_{\mathbf{C O}}$-b (Fig. S2). CCDC 988783-988788. For ESI and crystallographic data in CIF or other electronic format see DOI: 10.1039/c4dt00600c
}

The coordination chemistry of manganese(I) carbonyls has been explored because of their utility as catalysts (both carbon monoxide ${ }^{3}$ as well as studies in fundamental coordination chemistry. Coordination complexes of manganese carbo- 
carbonyls of $\mathrm{Mn}(\mathrm{I})$ are isoelectronic with their $\mathrm{Fe}(\mathrm{II})$ counterparts, and therefore exhibit some similar structural and donor preferences. However mononuclear Fe(II) carbonyls derived from coordinating ligands with nitrogen and sulfur donors and that are free from stabilizing phosphines - are less represented in literature. Such iron complexes (especially mononuclear species) can be challenging to isolate, requiring low temperatures and dark conditions. ${ }^{10-15}$ In contrast, the $\mathrm{Mn}(\mathrm{I})$ carbonyls are thermally stable under ambient conditions in non-coordinating solvents, and exhibit a reduced sensitivity to light. Therefore, as an entry point to iron chemistry, we wished to explore the coordination of a tridentate NNS ligand frame with manganese carbonyls.

Inspection of crystallographically characterized thioether $\mathrm{Mn}(\mathrm{I})$ carbonyls reveals several interesting trends. Cationic complexes of $\mathrm{Mn}(\mathrm{I})$ carbonyls with fully bound thioether-S ligation have been previously reported, ${ }^{16,17}$ as in the case of $\left[(\mathrm{LS} 3) \mathrm{Mn}(\mathrm{CO})_{3}\right]^{+}$, where the identities of LS3 are given below. Select examples of complete LS2 ligation to neutral complexes also exist, as in the case of $\left[(\mathrm{LS} 2) \mathrm{Mn}(\mathrm{CO})_{3} \mathrm{X}\right]\left(\mathrm{R}=\mathrm{CH}_{3}, \mathrm{Ph}\right.$; $\mathrm{X}=\mathrm{Cl}, \mathrm{Br}$, respectively). ${ }^{18}$ However, incomplete ligation of thioether chelates is very common, especially in neutral complexes. For example, the supporting tripodal ligand in [(PS2)$\left.\mathrm{Mn}(\mathrm{CO})_{3} \mathrm{Br}\right]$ and the tetrapodal $\left[(\mathrm{LS} 4) \mathrm{Mn}(\mathrm{CO})_{3} \mathrm{Cl}\right]$ and leave one or two (respectively) thioether-S donor(s) unbound. ${ }^{19,20}$ This occurs even in some cationic complexes: the crown-type complexes $\left[\left([12] \mathrm{aneS}_{4}\right) \mathrm{Mn}(\mathrm{CO})_{3}\right]^{+}$and $\left[\left([15] \operatorname{aneS}_{3 / 5}\right) \mathrm{Mn}(\mathrm{CO})_{3}\right]^{+}$ also exhibit one and two unbound thioether(s) (respectively). ${ }^{21}$ Treatment of $\left[\left([12] \mathrm{aneS}_{3 / 4}\right) \mathrm{Mn}(\mathrm{CO})_{3}\right]^{+}$with $\mathrm{Me}_{3} \mathrm{NO}$ did provide the dicarbonyl species $\left[\left([12] \operatorname{aneS}_{4 / 4}\right) \mathrm{Mn}(\mathrm{CO})_{2}\right]^{+}$, wherein all 4 thioether-S were bound. ${ }^{21}$ Indeed, the authors of this report noted this was the first report of a thioether-stabilized $\{\mathrm{Mn}$ $\left.(\mathrm{CO})_{2}\right\}^{+}$fragment, which is typically only stabilized by phosphines and other strong $\sigma$-donating, $\pi$-accepting ligands. The $\left\{\mathrm{Mn}(\mathrm{CO})_{2}\right\}^{+}$fragment formed spontaneously under metalation conditions, although photolysis or exchange of coordinating solvent (MeCN, THF) can readily afford the $\left\{\mathrm{Mn}(\mathrm{CO})_{2}\right\}^{+}$unit in some cases. $^{22}$

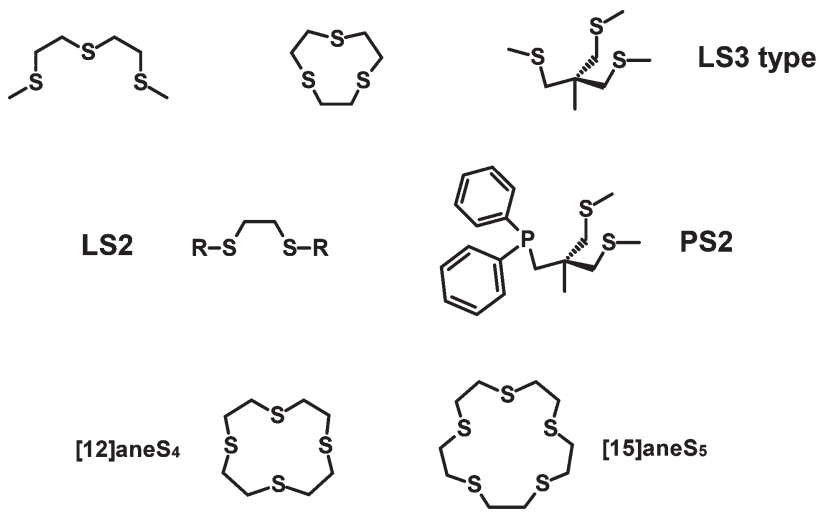

During the course of this work, Mascharak and co-workers reported the preparation of several manganese(I) carbonyls derived from Schiff base ligands, and their utility as photo- releasing $\mathrm{CO}$ reagent molecules (photoCORMs). ${ }^{23}$ Related photoactive manganese(I) tricarbonyls were also derived from diazopyridine, diimine N2, and N3 ligands. ${ }^{23-25}$ Most relevant to this work are complexes derived from similar Schiff base ligands with a pendant thioether-S. In the two cases of $\left[\left(\mathrm{L}_{N N S}\right)-\right.$ $\left.\mathrm{Mn}(\mathrm{CO})_{3}\right]^{+}\left(\mathrm{L}=\right.$ pmtpm and qmtpm; NNS and ${ }_{\mathrm{Q}} \mathrm{NNS}$ in our nomenclature), the thioether remained unbound. ${ }^{23}$ Indeed, to date there is just a single example of a mixed $\mathrm{N} / \mathrm{S}$ (thioether) ligand fully bound in a mononuclear complex, namely the complex $\left[\left(\mathrm{py}\left(\mathrm{CH}_{2}\right) \mathrm{SPh}\right) \mathrm{Mn}(\mathrm{CO})_{3} \mathrm{Br}\right]{ }^{26}$ Also, irrespective of ligand choice (N2S, N2, or N3) in all of these cases, only the tricarbonyl 'piano stool' congeners were isolated.

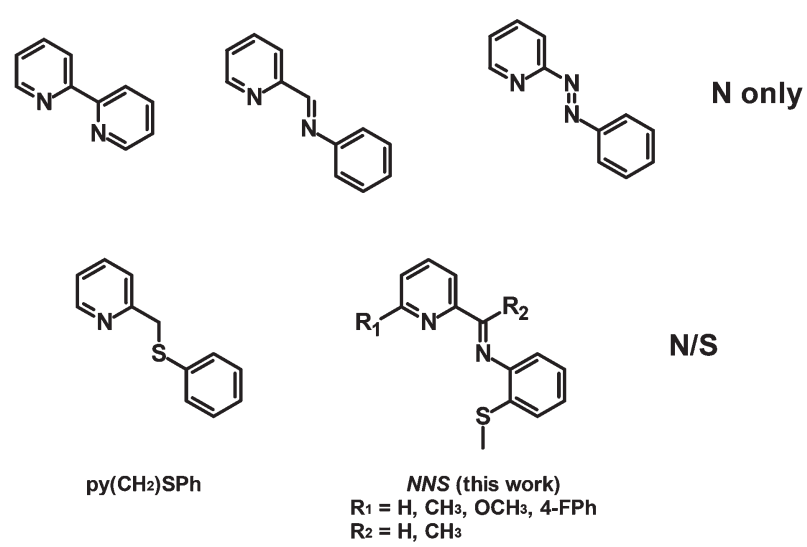

In this work, we attempted to circumvent difficulties associated with iron carbonyl chemistry, and utilize the more reliably mononuclear manganese congeners to explore the fundamental coordination chemistry of NNS type Schiff base ligands with metal carbonyls. As dimers readily form across thiolato-S bridges, we have also chosen a thioether moiety to allow for a sulfur donor, but to retain mononuclear motifs. Our work is focused on ligand optimization to ensure complete ligation of the chelate to the metal center, as well as structural and spectroscopic characterization of the resulting complexes. We show that careful selection of the ligand substituents (see substituted NNS framework above) leads to not only the fully bound NNS coordination motif, but also to a new example of a thioether-stabilized $\left\{\mathrm{Mn}(\mathrm{CO})_{2}\right\}^{+}$motif in the obligatory cis arrangement.

\section{Experimental}

\section{General procedures}

The manganese starting material $\left[\mathrm{Mn}(\mathrm{CO})_{5} \mathrm{Br}\right]$ was obtained from Strem Chemicals. All other reagents were obtained from Sigma Aldrich or Acros and used without further purification. For ligand preparation, solvents $\left(\mathrm{MeOH}, \mathrm{CH}_{2} \mathrm{Cl}_{2}, \mathrm{AcOH}\right)$ were purchased from Fisher and used without further purification. For metalation reactions, the $\mathrm{CH}_{2} \mathrm{Cl}_{2}, \mathrm{Et}_{2} \mathrm{O}$ and pentane were dried over an alumina column under argon atmosphere. All metalations and crystallizations were performed under $\mathrm{N}_{2}$ 
atmosphere. Deuterated solvents were obtained from Cambridge Isotopes or Acros Organics. Several aldehyde-derived ligands (NNS and $\mathbf{M e} \mathbf{N N S}$ ) were prepared according to literature reports. ${ }^{27,28}$ We independently devised an analogous synthesis of $\left[(\mathrm{NNS}) \mathrm{Mn}(\mathrm{CO})_{3} \mathrm{Br}\right]$ compared with a recently published report. $^{23}$

\section{Ligands}

oMe NNS. 1-(6-Methoxy-2-pyridyl)- $N$-(2-methylsulfanylphenyl)methanimine. A batch of 6-methoxy-2-pyridinecarboxaldehyde $(2.00 \mathrm{~g}, 14.6 \mathrm{mmol}$ ) was dissolved in $20 \mathrm{~mL}$ of $\mathrm{MeOH}$. To this stirred solution was added a solution of 2-(methylthio)aniline $(2.03 \mathrm{~g}, 14.6 \mathrm{mmol})$ in $15 \mathrm{~mL}$ of $\mathrm{MeOH}$. The solution was heated to reflux temperature for $2 \mathrm{~h}$, at which point it was cooled to ambient temperature and solvent evaporated under a stream of $\mathrm{N}_{2}$ gas. The resulting tacky solid was triturated $2 \times$ with $\mathrm{Et}_{2} \mathrm{O}$ to yield an orange solid. Selected IR bands $\left(\nu\right.$ in $\left.\mathrm{cm}^{-1}\right): 1623 \mathrm{w}$, 1587 m, 1567 s, 1462 s, 1439 s, 1321 m, 1138 w, 800 vs, 750 vs, $725 \mathrm{vs}, 635 \mathrm{w}, 538 \mathrm{~m} .{ }^{1} \mathrm{H}$ NMR in $\mathrm{CDCl}_{3}$ ( $\delta$ from TMS): $8.44 \mathrm{~s}$ $(1 \mathrm{H}), 7.90 \mathrm{~d}(1 \mathrm{H}), 7.68 \mathrm{t}(1 \mathrm{H}), 7.23 \mathrm{br}(1 \mathrm{H}), 7.16 \mathrm{br}(1 \mathrm{H}), 7.08$ br $(1 \mathrm{H}), 6.82 \mathrm{~d}(1 \mathrm{H}), 6.75 \mathrm{br}(1 \mathrm{H}), 4.00 \mathrm{~s}(3 \mathrm{H}), 2.47 \mathrm{~s}$ br $(3 \mathrm{H})$. HRMS calcd: 257.0749, 258.0827, 259.0905; found: 257.0756, 258.0833, 259.0903. NMR analysis indicated unreacted ( 30\%) aldehyde that was not separated by fractional crystallization or chromatography. The mixture was used in subsequent metalations.

${ }_{\text {FPh }}$ NNS. $\quad N$-((6-(4-Fluorophenyl)pyridin-2-yl)methylene)-2(methylthio)aniline. A small batch of 6-(4-fluorophenyl)-2-pyridinecarboxaldehyde $(0.289 \mathrm{~g}, 1.434 \mathrm{mmol})$ was dissolved in $25 \mathrm{~mL}$ of $\mathrm{MeOH}$. To this stirred solution was added a solution of 2-(methylthio)aniline dissolved in $5 \mathrm{~mL}$ of $\mathrm{MeOH}$. The reaction mixture was gently refluxed for $1 \mathrm{~h}$, and then the solvent removed in vacuo. The resulting residue was washed with a small portion of cold pentane, and the product was collected as a yellow solid. Yield: $351 \mathrm{mg}$ (76\%). Selected IR bands ( $\nu$ in $\mathrm{cm}^{-1}$ ): $1622 \mathrm{~m}, 1600 \mathrm{~m}, 1586 \mathrm{~m}, 1451 \mathrm{~s}, 1351 \mathrm{w}, 1213 \mathrm{~s}, 810 \mathrm{vs}$, $642 \mathrm{w}, 566 \mathrm{~s} .{ }^{1} \mathrm{H}$ NMR in $\mathrm{CDCl}_{3}$ ( $\delta$ in ppm from TMS): $8.64 \mathrm{~s}$ (1H), $8.25 \mathrm{~d}(1 \mathrm{H}), 8.03 \mathrm{dd}(2 \mathrm{H}), 7.90-7.84 \mathrm{~m}(2 \mathrm{H}), 7.73 \mathrm{~d}(1 \mathrm{H})$, $7.32 \mathrm{~s}$ br $(1 \mathrm{H}), 7.16 \mathrm{t}(1 \mathrm{H}), 7.10 \mathrm{~m} \mathrm{br}(2 \mathrm{H}) 6.70 \mathrm{~s}$ br $(1 \mathrm{H}), 2.46 \mathrm{~s}$ $(3 \mathrm{H})$. HRMS calcd: 321.0862, 322.0940, 323.1018; found: 321.0860, 322.0939, 323.1010.

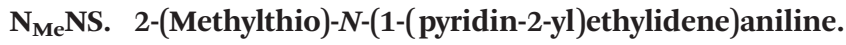
The 2-(methylthio)aniline $(0.500 \mathrm{~g}, 3.59 \mathrm{mmol})$ was diluted in $5 \mathrm{~mL}$ of acetic acid, and to this solution was added 2-acetylpyridine $(0.434 \mathrm{~g}, 3.59 \mathrm{mmol})$ in $5 \mathrm{~mL}$ of $\mathrm{AcOH}$. Next, a slurry of $\mathrm{ZnCl}_{2}(0.489 \mathrm{~g}, 3.59 \mathrm{mmol})$ in $5 \mathrm{~mL}$ of $\mathrm{AcOH}$ was added, and the reaction refluxed for $1 \mathrm{~h}$ to generate an orange solution (when hot). Upon cooling a yellow solid forms, which was collected by filtration and washed with several portions of $\mathrm{Et}_{2} \mathrm{O}$. The solid was then dissolved in $\mathrm{CH}_{2} \mathrm{Cl}_{2}(25 \mathrm{~mL})$ and washed $2 \times$ in a separatory funnel with $0.25 \mathrm{M} \mathrm{K}_{2} \mathrm{C}_{2} \mathrm{O}_{4}$, and $2 \times$ with water. The organic layer was dried over $\mathrm{Na}_{2} \mathrm{SO}_{4}$ and evaporated to dryness by rotary evaporation to afford a yellow oil. Yield: $0.49 \mathrm{~g}(56 \%)$. Selected IR bands $\left(\nu\right.$ in $\left.\mathrm{cm}^{-1}\right)$ : $3052 \mathrm{w}, 2919 \mathrm{w}$, 1635 s, 1578 m, 1565 m, 1466 s, 1434 s, 1301 m, 993 w, 965 w, $780 \mathrm{vs}, 737 \mathrm{vs}, 649 \mathrm{w}, 621 \mathrm{~m} .{ }^{1} \mathrm{H}$ NMR in $\mathrm{CDCl}_{3}$ ( $\delta$ in ppm from
TMS): $8.66 \mathrm{~d}(1 \mathrm{H}), 8.39 \mathrm{~d}(1 \mathrm{H}), 7.79 \mathrm{t}(1 \mathrm{H}), 7.36 \mathrm{dt}(1 \mathrm{H}), 7.25 \mathrm{~d}$ (1H), $7.14 \mathrm{~m}(2 \mathrm{H}), 6.72 \mathrm{~d}(1 \mathrm{H}), 2.37 \mathrm{~s}(3 \mathrm{H}), 2.34(3 \mathrm{H})$. HRMS calcd: 241.0799, 242.0878, 243.0956; found: 241.0802, $242.0878,243.0959$.

\section{Complexes}

$\left[(\boldsymbol{N N S}) \mathbf{M n}(\mathbf{C O})_{3} \mathbf{B r}\right] \quad\left(\mathbf{1}_{\mathbf{C O}}\right)$. Under $\mathrm{N}_{2}$ atmosphere, $0.130 \mathrm{~g}$ $(0.471 \mathrm{mmol})$ of $\left[\mathrm{Mn}(\mathrm{CO})_{5} \mathrm{Br}\right]$ was stirred in $10 \mathrm{~mL}$ of DCM in a round bottom flask until a clear yellow-orange solution is obtained. In a separate round bottom flask, $0.110 \mathrm{~g}$ $(0.482 \mathrm{mmol})$ of ligand was dissolved in another $10 \mathrm{~mL}$ of $\mathrm{CH}_{2} \mathrm{Cl}_{2}$ to generate a yellow solution. The ligand/ $\mathrm{CH}_{2} \mathrm{Cl}_{2}$ solution was added dropwise to the $\left[\mathrm{Mn}(\mathrm{CO})_{5} \mathrm{Br}\right]$ solution. The mixture was stirred overnight and there was a slow color change from yellow to a dark red solution. The dark solution was subjected to vapor diffusion of pentane at room temperature, which resulted in small black/red crystals suitable for Xray diffraction. Yield: $71 \mathrm{mg}$ (34\%). Selected IR bands $(\nu$ in $\mathrm{cm}^{-1}, \nu_{\mathrm{CO}}$ in italics): $2023 \mathrm{~m}, 1918 \mathrm{~s}, 1867 \mathrm{~s}, 1590 \mathrm{w}\left(\nu_{\mathrm{CN}}\right), 1415$ w, $962 \mathrm{w}, 767 \mathrm{~s}, 581 \mathrm{~m}$. UV/vis in $\mathrm{CH}_{2} \mathrm{Cl}_{2}, \lambda$ in $\mathrm{nm}\left(\varepsilon\right.$ in $\mathrm{cm}^{-1}$ $\mathrm{M}^{-1}$ ): 323 (19 900); also see Table $3 .{ }^{1} \mathrm{H}$ NMR in $\mathrm{CD}_{2} \mathrm{Cl}_{2}$ ( $\delta$ from TMS): $9.27 \mathrm{~s}(1 \mathrm{H}), 8.99 \mathrm{~s}(1 \mathrm{H}), 8.48 \mathrm{~s}(1 \mathrm{H}), 8.08 \mathrm{~m}(2 \mathrm{H})$, 7.78-7.32 m (3H), $2.54 \mathrm{~s}(3 \mathrm{H})$. Elemental Analysis, calcd: C 42.97, H 2.70, N 6.26; found: C 42.82, H 2.71, N 6.50.

$\left[(\mathbf{M e O} N \mathbf{N S}) \mathbf{M n}(\mathbf{C O})_{3} \mathbf{B r}\right]\left(2_{\mathrm{CO}}\right)$. Under $\mathrm{N}_{2}$ atmosphere, $0.078 \mathrm{~g}$ $(0.284 \mathrm{mmol})$ of $\left[\mathrm{Mn}(\mathrm{CO})_{5} \mathrm{Br}\right]$ was stirred in $10 \mathrm{~mL}$ of DCM in a round bottom flask until a clear yellow-orange solution is obtained. In a separate round bottom flask, $0.071 \mathrm{~g}$ $(0.275 \mathrm{mmol})$ of $\mathbf{M e O}_{\mathbf{N N S}}$ ligand was dissolved in another $10 \mathrm{~mL}$ DCM to generate a pale yellow solution. The ligand/DCM solution was added dropwise to the $\left[\mathrm{Mn}(\mathrm{CO})_{5} \mathrm{Br}\right]$ solution. The mixture was stirred overnight and there was a slow color change from yellow to a dark blood-red solution. The dark solution was subjected to vapor diffusion of pentane at room temperature, which resulted in small red cubic crystals suitable for X-ray diffraction. Yield: $70 \mathrm{mg}$ (54\%). Selected IR bands $\left(\nu\right.$ in $\mathrm{cm}^{-1}$, $\nu_{\mathrm{CO}}$ in italics): $2056 \mathrm{~s}, 1934 \mathrm{~s}, 1905 v s, 1619 \mathrm{w}\left(\nu_{\mathrm{CN}}\right), 1478 \mathrm{~s}$, $1306 \mathrm{~m}, 957 \mathrm{w}, 627 \mathrm{~s}, 455 \mathrm{w}$. UV/vis in $\mathrm{CH}_{2} \mathrm{Cl}_{2}, \lambda$ in $\mathrm{nm}(\varepsilon$ in $\mathrm{cm}^{-1} \mathrm{M}^{-1}$ ): 354 (4070); also see Table 3. Elemental Analysis, calcd: C 42.79, H 2.96, N 5.87; found: C 40.47, H 3.09, N 5.95.

$\left[(\mathrm{Me} \mathbf{N N S}) \mathbf{M n}(\mathrm{CO})_{3} \mathrm{Br}\right]\left(\mathbf{3}_{\mathrm{CO}}\right)$. Under inert atmosphere, $0.130 \mathrm{~g}$ $(0.474 \mathrm{mmol})$ of $\left[\mathrm{Mn}(\mathrm{CO})_{5} \mathrm{Br}\right]$ was stirred in $15 \mathrm{~mL}$ of $\mathrm{CH}_{2} \mathrm{Cl}_{2}$ in a round bottom flask until completely dissolved. Separately, $0.106 \mathrm{~g}(0.437 \mathrm{mmol})$ of ${ }_{\mathrm{Me}} \mathrm{NNS}$ was diluted in $15 \mathrm{~mL}$ of $\mathrm{CH}_{2} \mathrm{Cl}_{2}$. The ligand/ $\mathrm{CH}_{2} \mathrm{Cl}_{2}$ solution was added dropwise to the [Mn$\left.(\mathrm{CO})_{5} \mathrm{Br}\right]$ solution. The mixture was stirred overnight and there was a slow color change from yellow to dark red-brown. The solution precipitated some dark material and was filtered with a celite pipette to extract the fine precipitate from solution. The solution was placed into a Schlenk flask and placed in $4{ }^{\circ} \mathrm{C}$ which resulted in large red-orange blocks suitable for X-ray diffraction. Yield: $144 \mathrm{mg}$ (72\%). Selected IR bands $\left(\nu\right.$ in $\mathrm{cm}^{-1}$, $\nu_{\mathrm{CO}}$ in italics): $2019 \mathrm{~m}, 1925 v s, 1618 \mathrm{w}\left(\nu_{\mathrm{CN}}\right), 1579 \mathrm{w}, 1263 \mathrm{w}$, $799 \mathrm{~m}, 626 \mathrm{~s}$. UV/vis in $\mathrm{CH}_{2} \mathrm{Cl}_{2}, \lambda$ in $\mathrm{nm}\left(\varepsilon\right.$ in $\left.\mathrm{cm}^{-1} \mathrm{M}^{-1}\right): 314$ (7490), 488 (1530); also see Table $3 .{ }^{1} \mathrm{H}$ NMR in $\mathrm{CD}_{2} \mathrm{Cl}_{2}$ ( $\delta$ from TMS): $8.46 \mathrm{~s}(1 \mathrm{H}), 7.91 \mathrm{t}(1 \mathrm{H}), 7.76 \mathrm{t}(2 \mathrm{H}), 7.52 \mathrm{~d}(1 \mathrm{H}), 7.39 \mathrm{~m}$ 
(2H), $7.31 \mathrm{t}(1 \mathrm{H}), 3.13 \mathrm{~s}(3 \mathrm{H}), 2.53 \mathrm{~s}(3 \mathrm{H})$. Elemental Analysis, calcd: C 44.27, H 3.06, N 6.07; found: C 43.94, H 3.12, N 6.00.

$\left[\left(\mathrm{Me}^{N N S}\right) \mathbf{M n}(\mathrm{Br})_{2}\right]\left(3_{\mathrm{Br}}\right)$. Method A. A reaction was prepared according to the procedure for $\mathbf{3}_{\mathbf{C O}}$ stated above $\left(\mathbf{3}_{\mathbf{C O}}\right.$ collected as precipitate), and the filtrate was subjected to vapor diffusion of $\mathrm{Et}_{2} \mathrm{O}$. This generated red crystals suitable for X-ray analysis. As the yield was $<10 \%$, we developed an alternative preparation. Method B. Under ambient atmosphere, $0.060 \mathrm{~g}$ $(0.218 \mathrm{mmol})$ of $\left[\mathrm{Mn}(\mathrm{CO})_{5} \mathrm{Br}\right]$ is stirred in $20 \mathrm{~mL}$ of $\mathrm{CH}_{2} \mathrm{Cl}_{2}$ in a round bottom flask until completely dissolved. Separately, $0.050 \mathrm{~g}(0.206 \mathrm{mmol})$ of ${ }_{\mathrm{Me}} \mathrm{NNS}$ is diluted in $20 \mathrm{~mL}$ of $\mathrm{Et}_{2} \mathrm{O}$. The $\mathrm{CH}_{2} \mathrm{Cl}_{2}$ solution of the Mn carbonyl was distributed to a series of small test tubes. Next, the $\mathrm{Et}_{2} \mathrm{O}$ solution of ligand was carefully layered on top of the Mn solution, and the mixture was capped and allowed to diffuse slowly for 1 week. This procedure afforded large red diamond shaped crystals suitable for X-ray diffraction. Yield: $27 \mathrm{mg}$ (29\%). Selected IR bands ( $\nu$ in $\mathrm{cm}^{-1}$ ): $1586 \mathrm{~m}\left(\nu_{\mathrm{CN}}\right), 1378 \mathrm{~m}, 962 \mathrm{~m}, 794 \mathrm{~s}, 766 \mathrm{~s}, 738 \mathrm{~s}$, $579 \mathrm{~m}$. Magnetic moment (solid state, $298 \mathrm{~K}$ ): $\mu_{\mathrm{eff}}=4.9 \mu_{\mathrm{B}}$. Elemental Analysis, calcd: C 36.79, H 3.09, N 6.13; found: C 36.78, H 3.05, N 6.02.

$\left[\left(\boldsymbol{N}_{\mathbf{M e}} \boldsymbol{N S}\right) \mathbf{M n}(\mathrm{CO})_{2} \mathrm{Br}\right]\left(\mathbf{4}_{\mathrm{CO}}\right)$. Under inert atmosphere, $0.146 \mathrm{~g}$ $(0.531 \mathrm{mmol})$ of $\left[\mathrm{Mn}(\mathrm{CO})_{5} \mathrm{Br}\right]$ was stirred in $10 \mathrm{~mL}$ of $\mathrm{CH}_{2} \mathrm{Cl}_{2}$ in a round bottom flask until completely dissolved. Separately, $0.108 \mathrm{~g}(0.446 \mathrm{mmol})$ of $\mathrm{N}_{\mathrm{Me}} \mathrm{NS}$ was diluted in $10 \mathrm{~mL}$ of $\mathrm{CH}_{2} \mathrm{Cl}_{2}$. The ligand/ $\mathrm{CH}_{2} \mathrm{Cl}_{2}$ solution was added dropwise to the $\left[\mathrm{Mn}(\mathrm{CO})_{5} \mathrm{Br}\right]$ solution. The mixture stirred overnight and there was a slow color change from yellow to dark red-orange. This red-orange solution was subjected to vapor diffusion of $\mathrm{Et}_{2} \mathrm{O}$ at room temperature, which resulted in black needles suitable for X-ray diffraction. Yield: $152 \mathrm{mg}$ (66\%). Selected IR bands ( $\nu$ in $\mathrm{cm}^{-1}, \nu_{\mathrm{CO}}$ in italics): $1918 \mathrm{~s}, 1847 \mathrm{~s}, 1594 \mathrm{w}\left(\nu_{\mathrm{CN}}\right), 1430 \mathrm{~m}, 1256$ w, $965 \mathrm{~m}$. ${ }^{1} \mathrm{H}$ NMR in $\mathrm{CD}_{2} \mathrm{Cl}_{2}$ : see main text. UV/vis in $\mathrm{CH}_{2} \mathrm{Cl}_{2}$, $\lambda$ in $\mathrm{nm}\left(\varepsilon\right.$ in $\mathrm{cm}^{-1} \mathrm{M}^{-1}$ ): 319 (7450), 560 (510); also see Table $3 .{ }^{1} \mathrm{H}$ NMR in $\mathrm{CD}_{2} \mathrm{Cl}_{2}$ ( $\delta$ from TMS): two species observed; see main text. Elemental Analysis, calcd: C 44.36, H 3.26, N 6.47; found: C 43.53, H 3.30, N 6.33.

Subspecies of $\mathrm{FPh} \mathrm{NNS}:\left[(\mathrm{FPh} \mathrm{NNS}) \mathrm{Mn}(\mathrm{CO})_{3} \mathrm{Br}\right]\left(5_{\mathrm{CO}-\mathrm{a}}\right)$ and $\left[\left({ }_{\mathbf{F P h}} \mathbf{N N S}\right) \mathbf{M n}(\mathbf{C O})_{2} \mathbf{B r}\right]\left(\mathbf{5}_{\mathbf{C O}-\mathrm{b}}\right)$. Under $\mathrm{N}_{2}$ atmosphere, $0.113 \mathrm{~g}$ $(0.411 \mathrm{mmol})$ of $\left[\mathrm{Mn}(\mathrm{CO})_{5} \mathrm{Br}\right]$ was stirred in $10 \mathrm{~mL}$ of DCM in a round bottom flask until a clear yellow-orange solution is obtained. In a separate round bottom flask, $0.108 \mathrm{~g}$ $(0.335 \mathrm{mmol})$ of ${ }_{\mathbf{F P h}} \mathbf{N N S}$ ligand was dissolved in another $10 \mathrm{~mL}$ DCM to generate a yellow solution. The ligand/DCM solution was added dropwise to the $\left[\mathrm{Mn}(\mathrm{CO})_{5} \mathrm{Br}\right]$ solution. The mixture stirred overnight and there was a slow color change from yellow to a dark maroon-red solution. The reaction was split into two equal portions. Portion A. The first dark solution was subjected to vapor diffusion of pentane at room temperature (12-24 h), which resulted in small red cubic crystals of $\mathbf{5}_{\mathbf{C O}-\mathbf{a}}(\mathrm{S}$ unbound) suitable for X-ray diffraction. Yield: $68 \mathrm{mg}$ (Yield: 44\%). Selected IR bands ( $\nu$ in $\mathrm{cm}^{-1}, \nu_{\mathrm{CO}}$ in italics): $2021 \mathrm{~s}, 1943$ $s, 1914 v s, 1603 \mathrm{w}\left(\nu_{\mathrm{CN}}\right), 1423 \mathrm{~m}, 1224 \mathrm{~s}, 846 \mathrm{vs}, 733 \mathrm{~s}, 545 \mathrm{~m}$. $\mathrm{UV} /$ vis in $\mathrm{CH}_{2} \mathrm{Cl}_{2}, \lambda$ in $\mathrm{nm}\left(\varepsilon\right.$ in $\left.\mathrm{cm}^{-1} \mathrm{M}^{-1}\right)$ : 497 (1120). Elemental Analysis, calcd: C 48.82, H 2.79, N 5.18; found: C 48.67, $\mathrm{H}$ $2.70, \mathrm{~N} 5.21$. Portion $\mathrm{B}$. To the second portion of the reaction solution: slow vapor diffusion of $\mathrm{Et}_{2} \mathrm{O}$ ( 1 to 3 days) afforded black needles of $\mathbf{5}_{\mathbf{C O}-\mathbf{b}}$ ( $\mathrm{S}$ bound) suitable for X-ray diffraction. Yield: $73 \mathrm{mg}$ (Yield: $46 \%)$. Selected IR bands $\left(\nu\right.$ in $\mathrm{cm}^{-1}, \nu_{\mathrm{CO}}$ in italics): $1934 s, 1872 v s, 1607 \mathrm{~m}\left(\nu_{\mathrm{CN}}\right), 1474 \mathrm{~s}, 1171 \mathrm{~s}, 839 \mathrm{w}$, 749 vs, 519 w. UV/vis in $\mathrm{CH}_{2} \mathrm{Cl}_{2}, \lambda$ in $\mathrm{nm}\left(\varepsilon\right.$ in $\left.\mathrm{cm}^{-1} \mathrm{M}^{-1}\right): 332$ (3250), 612 (495); also see Table 3. Elemental Analysis, calcd: C 49.14, H 2.95, N 5.46; found: C 48.84, H 2.82, N 5.47.

\section{Physical measurements}

${ }^{1} \mathrm{H}$ NMR spectra of ligands were collected on Varian DirecDrive $400 \mathrm{MHz}$ spectrometer and chemical shifts were referenced to TMS. ${ }^{1} \mathrm{H}$ NMR spectra of the manganese complexes were recorded on a $500 \mathrm{MHz}$ Varian Inova instrument fitted with a variable temperature apparatus. UV/vis absorption spectra were obtained using an Ocean Optics USB2000+XRS-ES detector probed with a PX2 pulsed xenon lamp. Solutions of the complexes were prepared at $\sim 0.1 \mathrm{mM}$ in $1 \mathrm{~cm}$ quartz cuvettes in an argon drybox, and absorbances were measured with the aid of fiber optic feedthroughs. Infrared spectra of complexes in the solid state were recorded under ambient atmosphere on a Bruker Alpha spectrometer equipped with a diamond ATR crystal. The solid state magnetic moment of $\mathbf{3}_{\mathbf{B r}}$ was determined using a Johnson-Mathey magnetic susceptibility balance.

\section{X-ray diffraction data collection and crystal structure refinement}

The data were collected on either a Rigaku AFC12 diffractometer with a Saturn $724+$ CCD or on a Nonius Kappa CCD diffractometer using a Bruker AXS Apex II detector, both using a graphite monochromator with MoKo radiation. Reduced temperatures were maintained using an Oxford Cryostream low temperature device. Data reduction were performed using the Rigaku Crystal Clear version 1.40.2. Structures were solved by direct methods using SIR973 and refined by full-matrix least-squares on $F^{2}$ with anisotropic displacement parameters for the non-H atoms using SHELXL-97.4. Structure analysis was aided by use of the programs PLATON985 and WinGX.6. The hydrogen atoms on carbon were calculated in ideal positions with isotropic displacement parameters set to $1.2 U_{\text {eq }}$ of the attached atom $\left(1.5 U_{\text {eq }}\right.$ for methyl hydrogen atoms). For $\mathbf{5}_{\mathbf{C O}-\mathbf{b}}$, a large peak persisted in the difference electron density map $2.4 \AA$ from Mn. Additional but much smaller peaks were observed near $\mathrm{Br} 1$. These peaks were interpreted to be from a five coordinate $\mathrm{Mn}$ complex with one $\mathrm{Br}$ atom and one carbonyl group present in small quantities within the crystal. As such, the structure was modeled as a disordered species where the lone carbonyl group resides near the $\mathrm{Br}$ atom of the six coordinate species. The $\mathrm{Br}$ atom of the five coordinate species resides between the two carbonyl groups of the six coordinate complex. The relative occupancies of the two species were estimated by assigning the variable $x$ to the site occupancy for $\operatorname{Br} 1$ and $(1-x)$ to the site occupancy for Br1a. A common isotropic displacement parameter was refined for the two $\mathrm{Br}$ atoms while refining the variable $x$. In this way, the site occupancy for Br1 refined to $96(1) \%$. 
Table 1 Crystal data and refinement parameters

\begin{tabular}{|c|c|c|c|c|c|c|}
\hline & $\begin{array}{l}2_{\mathrm{CO}}[(\mathrm{ome} N N \mathrm{~S})- \\
\left.\mathrm{Mn}(\mathrm{CO})_{3} \mathrm{Br}\right]\end{array}$ & $\begin{array}{l}3_{\mathrm{Co}} \cdot \mathrm{CH}_{2} \mathrm{Cl}_{2}\left[\left(\mathrm{Me}_{\mathrm{NNS}}\right)-\right. \\
\left.\mathrm{Mn}(\mathrm{CO})_{3} \mathrm{Br}\right] \cdot \mathrm{CH}_{2} \mathrm{Cl}_{2}\end{array}$ & $\begin{array}{l}3_{\mathrm{Br}}[(\mathrm{Me} N N S)- \\
\left.\operatorname{Mn}(\mathrm{Br})_{2}\right]\end{array}$ & $\begin{array}{l}\mathbf{4}_{\mathrm{Co}}\left[\left(N_{\mathrm{Me}} N S\right)-\right. \\
\left.\operatorname{Mn}(\mathrm{CO})_{2} \mathrm{Br}\right]\end{array}$ & $\begin{array}{l}\mathbf{5}_{\mathrm{CO}-\mathrm{a}}[(\mathrm{FPh} N N S)- \\
\left.\mathrm{Mn}(\mathrm{CO})_{3} \mathrm{Br}\right]\end{array}$ & $\begin{array}{l}\mathbf{5}_{\mathrm{CO}-\mathbf{b}}[(\mathrm{FPh} N N S)- \\
\left.\mathrm{Mn}(\mathrm{CO})_{2} \mathrm{Br}\right]\end{array}$ \\
\hline Formula & $\mathrm{C}_{17} \mathrm{H}_{14} \mathrm{~N}_{2} \mathrm{O}_{4} \mathrm{BrSMn}$ & $\mathrm{C}_{18} \mathrm{H}_{16} \mathrm{~N}_{2} \mathrm{O}_{3} \mathrm{BrSMn}$ & $\mathrm{C}_{14} \mathrm{H}_{14} \mathrm{~N}_{2} \mathrm{Br}_{2} \mathrm{SMn}$ & $\mathrm{C}_{16} \mathrm{H}_{14} \mathrm{BrMnN}_{2} \mathrm{O}_{2} \mathrm{~S}$ & $\mathrm{C}_{22} \mathrm{H}_{15} \mathrm{~N}_{2} \mathrm{O}_{3} \mathrm{SBrFMn}$ & $\mathrm{C}_{21} \mathrm{H}_{15} \mathrm{~N}_{2} \mathrm{O}_{2} \mathrm{SBrFMn}$ \\
\hline Color & Red & Red & Orange & Black & Orange & Black \\
\hline Habit & Plate & Block & Block & Needle & Plate & Needles \\
\hline Size $(\mathrm{mm})$ & $0.36 \times 0.21 \times 0.09$ & $0.65 \times 0.41 \times 0.11$ & $0.30 \times 0.14 \times 0.09$ & $0.27 \times 0.21 \times 0.12$ & $0.34 \times 0.23 \times 0.11$ & $0.17 \times 0.13 \times 0.08$ \\
\hline$T(\mathrm{~K})$ & $163(2)$ & $163(2)$ & $173(2)$ & 153(2) & $153(2)$ & $100(2)$ \\
\hline Space group & $P \overline{1}$ & $P \overline{1}$ & $P_{2} 1 / n$ & $P_{2} 1 / n$ & $P_{2} 1 / n$ & $P_{2} 1 / c$ \\
\hline$a(\AA)$ & $7.5300(3)$ & $8.7613(3)$ & $11.838(3)$ & $8.7752(19)$ & $7.9074(5)$ & $13.942(5)$ \\
\hline$b(\AA)$ & $7.6723(3)$ & $10.8921(4)$ & $10.124(3)$ & $12.659(3)$ & $21.6449(14)$ & $11.412(5)$ \\
\hline$c(\AA)$ & $17.7327(6)$ & $13.0888(5)$ & $13.654(4)$ & $14.644(3)$ & $12.5018(6) \AA$ & $14.573(4)$ \\
\hline$\alpha\left({ }^{\circ}\right)$ & $87.250(2)$ & $66.319(2)$ & 90 & 90 & 90 & 90 \\
\hline$\beta\left({ }^{\circ}\right)$ & $79.371(2)$ & $79.790(2)$ & $102.610(7)$ & $92.798(5)$ & $96.094(2)$ & $117.66(3)$ \\
\hline$\gamma\left(0^{\circ}\right)$ & $66.350(2)$ & $69.483(2)$ & 90 & 90 & 90 & 90 \\
\hline GOF on $F^{2}$ & 1.122 & 1.031 & 0.999 & 1.112 & 1.121 & 1.110 \\
\hline$R$ indices $[I>2 \sigma(I)]$ & $\begin{array}{l}R_{1}=0.0232 \\
\mathrm{w} R_{2}=0.0676\end{array}$ & $\begin{array}{l}R_{1}=0.0350 \\
\mathrm{w} R_{2}=0.0792\end{array}$ & $\begin{array}{l}R_{1}=0.0872 \\
\mathrm{w} R_{2}=0.2012\end{array}$ & $\begin{array}{l}R_{1}=0.0310 \\
\mathrm{w} R_{2}=0.0735\end{array}$ & $\begin{array}{l}R_{1}=0.0284 \\
\mathrm{w} R_{2}=0.0661\end{array}$ & $\begin{array}{l}R_{1}=0.0553 \\
\mathrm{w} R_{2}=0.1205\end{array}$ \\
\hline$R$ indices all data & $\begin{array}{l}R_{1}=0.0273 \\
\mathrm{w} R_{2}=0.0700\end{array}$ & $\begin{array}{l}R_{1}=0.0412 \\
\mathrm{w} R_{2}=0.0842\end{array}$ & $\begin{array}{l}R_{1}=0.1217 \\
\mathrm{w} R_{2}=0.2242\end{array}$ & $\begin{array}{l}R_{1}=0.0365 \\
\mathrm{w} R_{2}=0.0759\end{array}$ & $\begin{array}{l}R_{1}=0.0411 \\
\mathrm{w} R_{2}=0.0710\end{array}$ & $\begin{array}{l}R_{1}=0.0725 \\
\mathrm{w} R_{2}=0.1280\end{array}$ \\
\hline
\end{tabular}

The ratio of the six coordinate species in the crystal to the five coordinate species is 24:1. After an initial refinement, the coordinates for $\mathrm{O} 1 \mathrm{a}$ and $\mathrm{C} 2 \mathrm{a}$ were fixed along with their displacement parameters in the final refinement model. The data collection and refinement parameters are listed in Table 1.

\section{Results and discussion}

\section{Syntheses}

The NNS ligands derived from aldehyde starting materials (denoted ${ }_{\mathbf{R} 1} \mathbf{N N S}$ ) were prepared under reported conditions (condensation in $\mathrm{MeOH}){ }^{27,28}$ The novel iminomethyl-substituted ligands (ketone starting materials; denoted ${ }_{\mathbf{R} 1} \mathbf{N}_{\mathbf{M e}} \mathbf{N S}$ ) were prepared by a zinc-templated reaction $\left(\mathrm{AcOH}, \mathrm{ZnCl}_{2}\right.$, reflux) with 2 -(methylthio)aniline. The resulting zinc-bound intermediate was de-metalated by treatment with aqueous oxalate, allowing extraction of the free ligand into the organic layer.

We pursued the metalation of NNS-type ligands with [Mn$\left.(\mathrm{CO})_{5} \mathrm{Br}\right]$ under reported conditions $\left(\mathrm{CH}_{2} \mathrm{Cl}_{2}\right.$, room temperature, $\mathrm{N}_{2}$ atmosphere). ${ }^{17-23}$ In general, the reaction of a yellow solutions of NNS and $\left[\mathrm{Mn}(\mathrm{CO})_{5} \mathrm{Br}\right]$ generated a dark red color over the course of $15 \mathrm{~min}$ to 1 hour. Vapor diffusion of pentane or $\mathrm{Et}_{2} \mathrm{O}$ afforded crystalline material that ranged from black to translucent orange. We found that ligation of the thioether-S donor was dependent on the nature of the Schiff base R-group. As shown in Scheme 1, metalations of aldehydederived ligands afford the NNS bound complex of type $\left[\left({ }_{\mathrm{R}} N N S\right)\right.$ $\left.\mathrm{Mn}(\mathrm{CO})_{3} \mathrm{Br}\right]$. Coincidentally, the same reaction was reported by Mascharak and co-workers during preparation of this manuscript using the same NNS ligand, as well as its quinoline con-

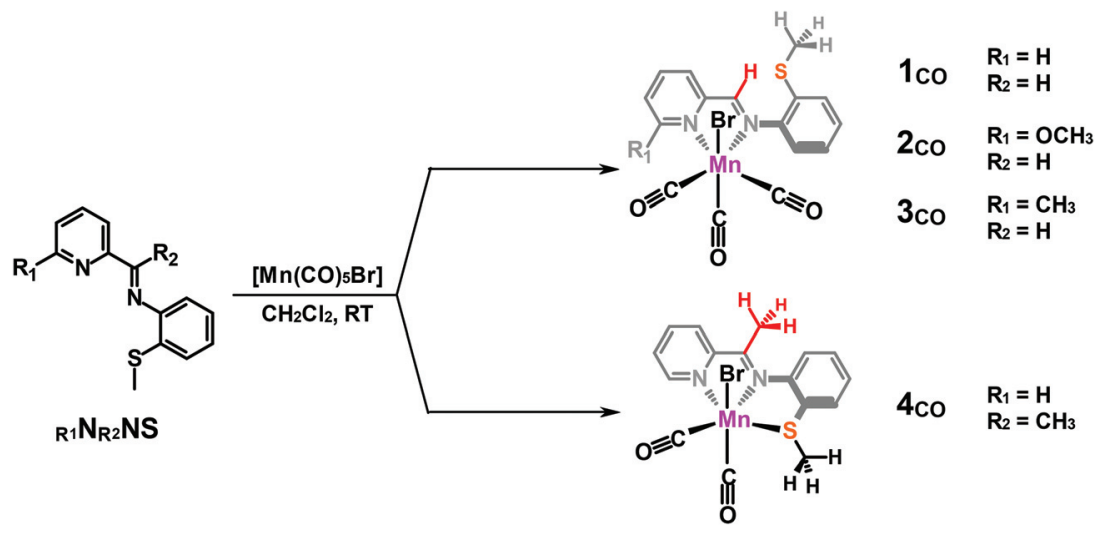

Scheme 1 Metalation of substituted NNS ligands with $\left[\mathrm{Mn}(\mathrm{CO})_{5} \mathrm{Br}\right]$; the coordination mode is dependent on $\mathrm{R}_{2}$. 

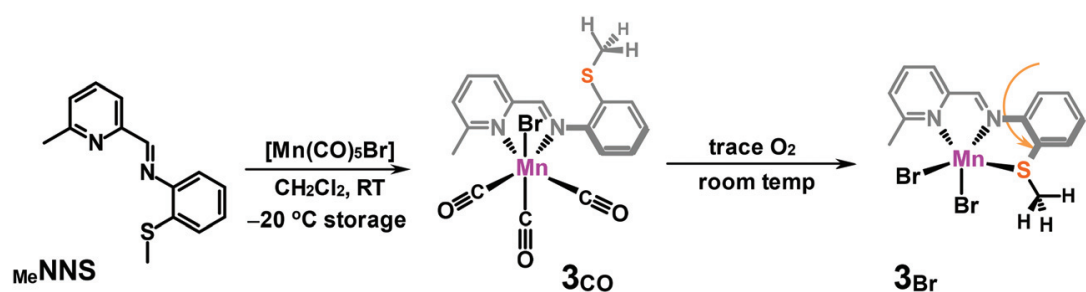

$3 \mathrm{Br}$

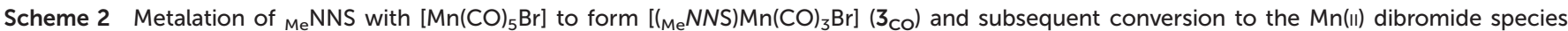
$\left[\left(\mathrm{Me}_{\mathrm{N}} \mathrm{NNS}\right) \mathrm{Mn}(\mathrm{Br})_{2}\right]\left(3_{\mathrm{Br}}\right)$.

gener. ${ }^{23}$ This trend of the unbound thioether-S is largely independent of the R-group at the ortho position of the pyridine moiety $\left(\mathrm{H}, \mathrm{CH}_{3}, \mathrm{OCH}_{3}\right)$. Conversely, substitution of a methyl group at the Schiff base affords the fully ligated complex $\left[\left(N_{\mathrm{Me}} N S\right) \mathrm{Mn}(\mathrm{CO})_{2} \mathrm{Br}\right]$. Binding of the thioether is likely encouraged by steric repulsion between the Schiff base $-\mathrm{CH}_{3}$ group and the aryl(methyl)thioether unit in the S-unbound state (vide infra, X-ray section).

The manganese carbonyls are generally stable in $\mathrm{CH}_{2} \mathrm{Cl}_{2}$ solution at $298 \mathrm{~K}$ under $\mathrm{N}_{2}$, even in presence of trace amounts of $\mathrm{O}_{2}$. One exception is the 2-methylpyridine complex [( $\mathrm{MeNNS}$ $\left.\mathrm{Mn}(\mathrm{CO})_{3} \mathrm{Br}\right]$, which crystallized in sufficient purity only at $-20{ }^{\circ} \mathrm{C}$. At ambient temperature (and with trace $\mathrm{O}_{2}$ ), this complex transforms to the Mn(II) dibromide complex [( $\mathrm{Me}^{N N S)}$ $\left.\mathrm{Mn}(\mathrm{Br})_{2}\right]$, in which the chelate is fully ligated (Scheme 2).

\section{X-ray structures}

$\left[\left({ }_{\mathrm{H}} \mathrm{NNS}\right) \mathrm{Mn}(\mathrm{CO})_{3}(\mathrm{Br})\right]\left(\mathbf{1}_{\mathrm{CO}}\right)$. During the course of this work, the X-ray structure of $\mathbf{1}_{\mathrm{CO}}$ was reported by another research group. ${ }^{23}$ For the purpose of comparison to the other complexes, we briefly describe the metrics of the reported complex here. Similar to $\mathbf{2}_{\mathbf{C O}}$ (Fig. 1), the manganese center in $\mathbf{1}_{\mathbf{C O}}$ is overall pseudo-octahedral, with the two $\mathrm{N}$ donors of the ligand bound to the metal center. The $\mathrm{Mn}-\mathrm{N}_{\mathrm{py}}$ and $\mathrm{Mn}-\mathrm{N}_{\mathrm{SB}}$ bond distances [2.054(2) and 2.049(2) $\AA$, respectively] are typical for lowspin, $\mathrm{Mn}(\mathrm{I})$ nitrogen bonds in complexes bearing the 2-iminomethene-pyridyl moiety. The thioether-S is not bound to the manganese center, with the aryl(thioether) moiety rotated at a dihedral angle of $65.9^{\circ}$ away from the planar pyridyl/Schiff

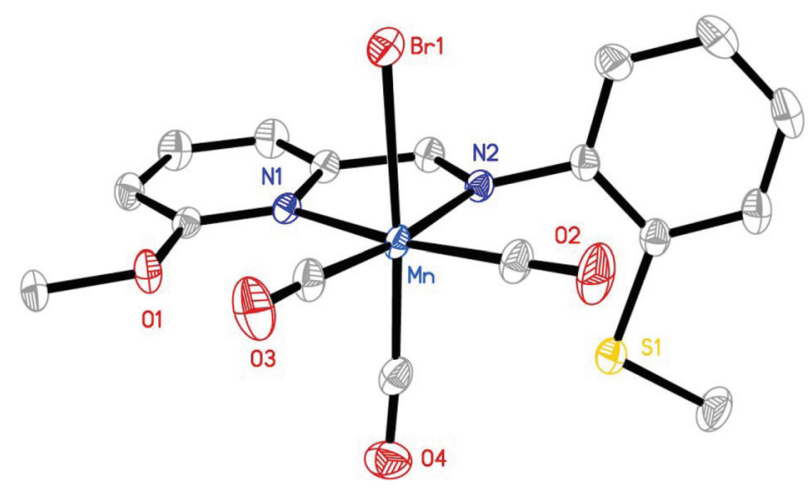

Fig. 1 ORTEP diagram (50\% ellipsoids) of [(омe $\left.N N S) M n(C O)_{3} \mathrm{Br}\right]\left(2_{\mathrm{CO}}\right)$. $\mathrm{H}$ atoms are omitted for clarity. base moiety. Because this distorts the otherwise planar, conjugated $\pi$-system of the ligand frame, this indicates a strong preference of the $\mathrm{Mn}(\mathrm{I})$ center for the back-bonding CO ligand versus the $\sigma$-donor only character of the thioether-S. There is, however, a somewhat close contact between the unbound $\mathrm{S}$ donor and the adjacent carbonyl - the $\mathrm{S} \cdots \mathrm{C}(\mathrm{O})$ distance is $\sim 3.9 \AA$. The three carbonyl ligands are bound in a facial arrangement (as nearly always found in tricarbonyls), and exhibit Mn-C(O) distances of 1.806(3), 1.781(4), 1.802(3) ^ the shortest of which is bound trans to the $\mathrm{Br}^{-}$ion. The $\mathrm{Mn}-\mathrm{Br}$ distance of 2.5338(5) $\AA$ is predictably long due to repulsion between the low-valent $\mathrm{Mn}(\mathrm{I})$ and bromide ion, and in a similar range to other $\mathrm{Mn}(\mathrm{I})$ carbonyl bromides.

$\left[\left({ }_{\text {ome }} N \mathrm{NS}\right) \mathbf{M n}(\mathrm{CO})_{3}(\mathrm{Br})\right]\left(2_{\mathrm{CO}}\right)$. The X-ray structure of the methoxy-appended complex $2_{\mathrm{CO}}$ is also shown in Fig. 1. Overall, the complex exhibits similarity to $\mathbf{1}_{\mathbf{C O}}$ in that the coordination geometry is pseudo-octahedral and the thioether moiety remains unbound; the three carbonyl ligands are also arranged in the same facially coordinating fashion. The Mn$\mathrm{N}_{\mathrm{py}}$ bond distance of 2.0844(15) $\AA$ is slightly longer than that found in $\mathbf{1}_{\mathrm{Co}}\left(\mathrm{Mn}-\mathrm{N}_{\mathrm{py}}=2.054(2) \AA\right)$, likely due to the steric repulsion due to the ortho methoxy group. The repulsion effect is not apparent in the $\mathrm{Mn}-\mathrm{N}_{\mathrm{SB}}$ bond distances found in $\mathbf{2}_{\mathrm{CO}}$ [2.0446(15) $\AA$ ) and $\mathbf{1}_{\text {CO }}(2.049(2) \AA]$. The methoxy-O is located $3.207 \AA$ away from the Mn center, distinctly outside the range of normal Mn-O bonding. Notably, the distance between the methoxy-O and the C-donor of the adjacent carbonyl is quite short - only $2.66 \AA$ A. As found in $\mathbf{1}_{\mathbf{C O}}$, there is a subtle interaction between the unbound thioether and a carbonyl ligand. This interaction appears to be more pronounced in the case of $\mathbf{2}_{\mathrm{CO}}[\mathrm{S} \cdots \mathrm{C}(\mathrm{O}) \approx 3.34 \AA]$ versus that observed in $\mathbf{1}_{\mathrm{Co}}[\mathrm{S} \cdots \mathrm{C}(\mathrm{O}) \approx$ $3.9 \AA$ A . This appears to occur in $2_{\text {Co }}$ due to a slightly greater twist of the aryl(methyl)thioether moiety $\left(70.0^{\circ}\right)$ versus that in $\mathbf{1}_{\text {CO }}\left(65.9^{\circ}\right)$. Interestingly, the largest differences in carbonyl ligand metrics between $\mathbf{2}_{\mathrm{CO}}$ and $\mathbf{1}_{\mathrm{CO}}$ occur at the carbonyl participating in the interaction with the thioether S moiety. While the $\mathrm{Mn}-\mathrm{C}-\mathrm{O}$ bond angles are nearly invariant in each complex $\left[174.03(18)^{\circ}, 174.86(16)^{\circ}\right]$, in $2_{\mathrm{CO}}$ the $\mathrm{Mn}-\mathrm{C}(\mathrm{O})$ and $(\mathrm{Mn}) \mathrm{C}-\mathrm{O}$ bonds [1.798(2), 1.126(3) $\AA$ ] are significantly longer than the same distances in $\mathbf{1}_{\text {CO }}$ [1.781(4), 1.148(4) $\AA$. This suggests the $\mathrm{S} \cdots \mathrm{C}(\mathrm{O})$ interaction is significant, and generates weaker bonding along the $\mathrm{Mn}-\mathrm{C}-\mathrm{O}$ axis due to partial donation of sulfur lone pair to the Lewis acidic carbonyl C. The remaining bond distances to the carbonyl and bromide ligands are unremarkable. 

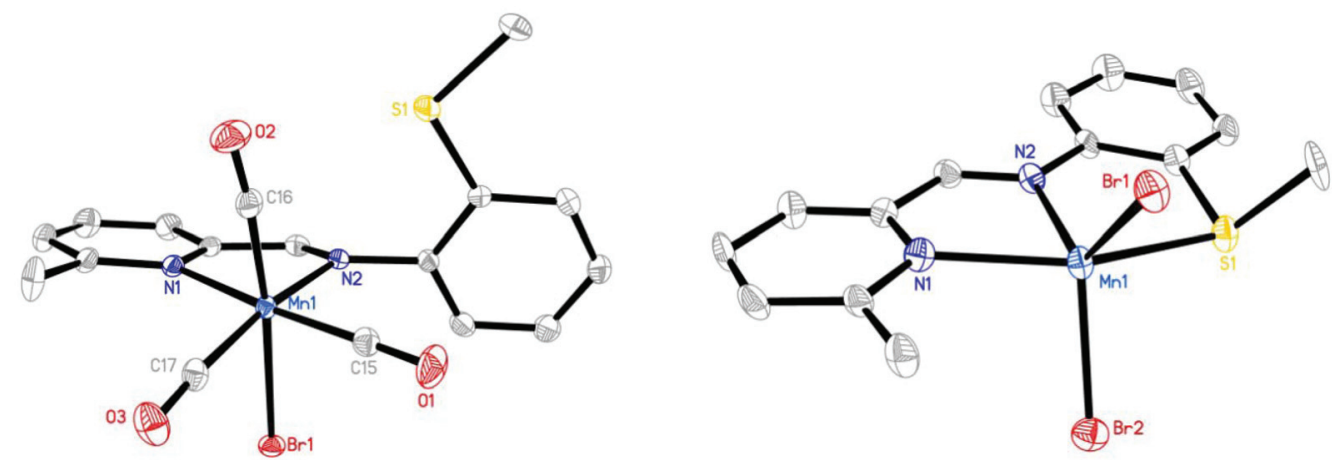

Fig. 2 ORTEP diagrams of the molecular structures of $\left[\left(\mathrm{Me}_{\mathrm{e}} \mathrm{NNS}\right) \mathrm{Mn}(\mathrm{CO}){ }_{3} \mathrm{Br}\right]\left(3_{\mathrm{CO}}, 50 \%\right.$ ellipsoids $)$ and $\left[(\mathrm{Me} N N S) \mathrm{Mn}(\mathrm{Br})_{2}\right]\left(3_{\mathrm{Br}}, 30 \%\right.$ ellipsoids). $\mathrm{H}$ atoms are omitted for clarity.

$\left[\left(\mathrm{Me}_{\mathrm{NNS}}\right) \mathbf{M n}(\mathbf{C O})_{3}(\mathrm{Br})\right] \quad\left(3_{\mathrm{CO}}\right)$. The X-ray structure of the 2-methylpyridine derived manganese carbonyl $\mathbf{3}_{\mathrm{CO}}$ is shown below in Fig. 2. This manganese species exhibits a similar binding mode and overall coordination geometry to $\mathbf{1}_{\mathrm{Co}}$ and $2_{\text {Co }}$. The steric effect of the 2-methyl group at the pyridine moiety is quite pronounced, resulting in a long $\mathrm{Mn}-\mathrm{N}_{\mathrm{py}}$ bond of 2.097(2) $\AA$, versus the corresponding $\mathrm{Mn}-\mathrm{N}_{\mathrm{py}}$ distance of 2.0844(15) $\AA$ and 2.054(2) $\AA$ in $2_{\mathrm{CO}}$ and $\mathbf{1}_{\mathrm{CO}}$, respectively. However the Schiff base N-donor remains bound at approximately the same distance (2.045(2) $\AA$ ) as found in $\mathbf{1}_{\mathrm{CO}}$ and $\mathbf{2}_{\mathrm{CO}}$. And although the $-\mathrm{CH}_{3}$ protons were not experimentally located in the diffraction map, the model suggests that the $\mathrm{CH}_{3} \cdots \mathrm{C}(\mathrm{O})$ distance is short - in the range of 2.6 to $2.7 \AA$ - and less than the sum of the van der Waals radii $(\sim 2.8 \AA)$. However, there is no resulting perturbation of the $\mathrm{Mn}-\mathrm{C}-\mathrm{O}$ bond metrics in $\mathbf{3}_{\mathrm{CO}}$ versus $\mathbf{2}_{\mathrm{CO}}$ or $\mathbf{1}_{\mathrm{CO}}$ that can be attributed to the infringing methyl unit. Interestingly, in $\mathbf{3}_{\mathrm{Co}}$ the $\mathrm{S} \cdots \mathrm{C}(\mathrm{O})$ interaction $(\sim 3.26 \AA)$ is closer than in $\mathbf{2}_{\mathbf{C O}}$ or $\mathbf{1}_{\mathbf{C O}}$, but unlike $2_{\mathrm{CO}}$ there is no significant change in $\mathrm{Mn}-\mathrm{C}-\mathrm{O}$ bond metrics versus $\mathbf{1}_{\mathrm{CO}}$. The remaining $\mathrm{Mn}-\mathrm{C}(\mathrm{O}), \mathrm{C}-\mathrm{O}$ and $\mathrm{Mn}-\mathrm{Br}$ distances are listed in Table 2.

$\left[\left({ }_{\mathrm{Me}} N N S\right) \mathbf{M n}(\mathrm{Br})_{2}\right]\left(3_{\mathrm{Br}}\right)$. The X-ray structure of the dibromide complex $\left[\left(\mathrm{Me}^{N N S}\right) \mathrm{Mn}(\mathrm{Br})_{2}\right]$ is shown in Fig. 2 (right side). Both the Mn-N [2.246(8), 2.245(8) $\AA$ ] and Mn-Br [2.4877(18),
2.4881(19) $\AA$ ] bond distances found in $3_{\mathrm{Br}}$ are longer than in the corresponding manganese carbonyl, due to the high-spin configuration of the complex (vide infra, Spectroscopy section). Of note is the fact that this complex is monomeric; many dihalide complexes of $\mathrm{Mn}$ (II) with bidentate or tridentate ligands exhibit a dimeric motif via a $\mu-(\mathrm{X})_{2}($ where $\mathrm{X}=\mathrm{Cl}, \mathrm{Br})$ bridge. It is likely that dimerization is prevented by the combined steric effects of the 2-methylpyridine and thioether $\mathrm{S}^{-\mathrm{CH}_{3}}$ units. Close inspection of the structural database reveals numerous examples of dimerized $\mathrm{Mn}_{2} \mathrm{Br}_{2}$ complexes. ${ }^{29-33}$ However, the arrangement of the capping ligands is always parallel and close-packed - a configuration not possible with the two pendant methyl units $\left(-\mathrm{SCH}_{3}\right.$ and ortho $\left.o_{\mathrm{py}}-\mathrm{CH}_{3}\right)$.

$\left[\left(N_{\mathrm{Me}} N S\right) \mathrm{Mn}(\mathrm{CO})_{2}(\mathrm{Br})\right] \quad\left(4_{\mathrm{CO}}\right)$. The tridentate NNS ligand bearing a methyl substituent at the Schiff base linkage in $\mathbf{4}_{\mathrm{CO}}$ is fully ligated in NNS fashion to the manganese center (Fig. 3). As a result, the $\mathrm{Mn}-\mathrm{N}_{\mathrm{py}}$ and $\mathrm{Mn}-\mathrm{N}_{\mathrm{SB}}$ bonds in $\mathbf{4}_{\mathrm{CO}}$ are much shorter (1.982(2) and 2.029(2) A, respectively) than those in $\mathbf{1}_{\mathbf{C O}}$, presumably due to the chelation effect of all three bound donor atoms. The Mn-S bond distance of 2.301(8) $\AA$ is similar to that found in the only other mixed $\mathrm{N} / \mathrm{S}$ (thioether) manganese carbonyl [2.3449(6), 2.3467(7) ̊]. ${ }^{26}$ The Mn-S bond length in $\mathbf{4}_{\mathrm{CO}}$ is also much shorter than in the Mn(II) dibromide species described herein $\left[2_{\mathrm{Br}}, 2.6839(13) ; 3_{\mathrm{Br}}, 2.645(3) \AA ̊ ․\right.$

Table 2 Selected bond distances $(\AA \AA)$ and bond angles $\left(^{\circ}\right)$

\begin{tabular}{|c|c|c|c|c|c|c|c|}
\hline $\mathrm{R}_{1}, \mathrm{R}_{2}$ & $\mathbf{1}_{\mathrm{CO}}{ }^{a} \mathrm{H}, \mathrm{H}$ & $2_{\mathrm{CO}} \mathrm{OCH}_{3}, \mathrm{H}$ & $3_{\mathrm{CO}} \mathrm{CH}_{3}, \mathrm{H}$ & $3_{\mathrm{Br}} \mathrm{CH}_{3}, \mathrm{H}$ & $\mathbf{4}_{\mathrm{CO}} \mathrm{H}, \mathrm{CH}_{3}$ & $\mathbf{5}_{\text {CO-a }} \mathrm{FPh}, \mathrm{H}$ & $\mathbf{5}_{\text {CO-b }} \mathrm{FPh}, \mathrm{H}$ \\
\hline $\mathrm{Mn}-\mathrm{N}_{\mathrm{py}}$ & $2.054(2)$ & $2.0844(15)$ & $2.097(2)$ & $2.246(8)$ & $1.987(2)$ & $2.0954(16)$ & $2.100(4)$ \\
\hline $\mathrm{Mn}-\mathrm{N}_{\mathrm{SB}}$ & $2.049(2)$ & $2.0446(15)$ & $2.045(2)$ & $2.245(8)$ & $2.029(2)$ & $2.0488(16)$ & $2.016(4)$ \\
\hline $\mathrm{Mn}-\mathrm{S}_{\mathrm{Me}}$ & - & - & - & $2.645(3)$ & $2.3001(8)$ & - & $2.3069(14)$ \\
\hline $\mathrm{Mn}-\mathrm{Br}$ & $2.5338(5)$ & $2.5216(3)$ & $2.5314(5)$ & $2.4877(18)$ & $2.5564(7)$ & $2.5250(4)$ & $2.5690(10)$ \\
\hline $\mathrm{Mn}-\mathrm{Br}$ & - & - & - & $2.4781(19)$ & - & - & - \\
\hline $\mathrm{Mn}-\mathrm{C}(\mathrm{O})$ trans $\mathrm{SB}$ & $1.806(3)$ & $1.815(2)$ & $1.809(3)$ & - & $1.789(3)$ & $1.824(2)$ & $1.805(5)$ \\
\hline$(\mathrm{Mn}) \mathrm{C}-\mathrm{O}$ trans SB & $1.148(3)$ & $1.140(2)$ & $1.139(4)$ & - & $1.155(3)$ & $1.144(2)$ & $1.145(5)$ \\
\hline $\mathrm{Mn}-\mathrm{C}(\mathrm{O})$ trans $\mathrm{Br}$ & $1.781(4)$ & $1.798(2)$ & $1.803(3)$ & - & $1.789(3)$ & $1.802(2)$ & $1.799(4)$ \\
\hline$(\mathrm{Mn}) \mathrm{C}-\mathrm{O}$ trans $\mathrm{Br}$ & $1.148(4)$ & $1.126(3)$ & $1.143(3)$ & - & $1.131(3)$ & $1.132(3)$ & $1.135(5)$ \\
\hline $\mathrm{Mn}-\mathrm{C}(\mathrm{O})$ trans $\mathrm{py}$ & $1.802(3)$ & $1.810(2)$ & $1.811(3)$ & - & - & $1.799(2)$ & - \\
\hline$(\mathrm{Mn}) \mathrm{C}-\mathrm{O}$ trans py & $1.148(3)$ & $1.140(3)$ & $1.142(4)$ & - & - & $1.147(2)$ & - \\
\hline Aryl-(SMe) Dihedral & 65.92 & 70.00 & 68.46 & 9.33 & 31.92 & 64.64 & 5.18 \\
\hline $\mathrm{S} \cdots \mathrm{C}(\mathrm{O})_{\mathrm{Br}}$ & 3.900 & 3.338 & 3.258 & - & - & 4.128 & - \\
\hline $\mathrm{R}_{1} \cdots \mathrm{C}(\mathrm{O})_{\mathrm{SB}}$ & 2.646 & 2.666 & $\sim 2.65$ & - & 2.694 & 2.947 & 3.097 \\
\hline
\end{tabular}

${ }^{a}$ Values taken from ref. 23. 


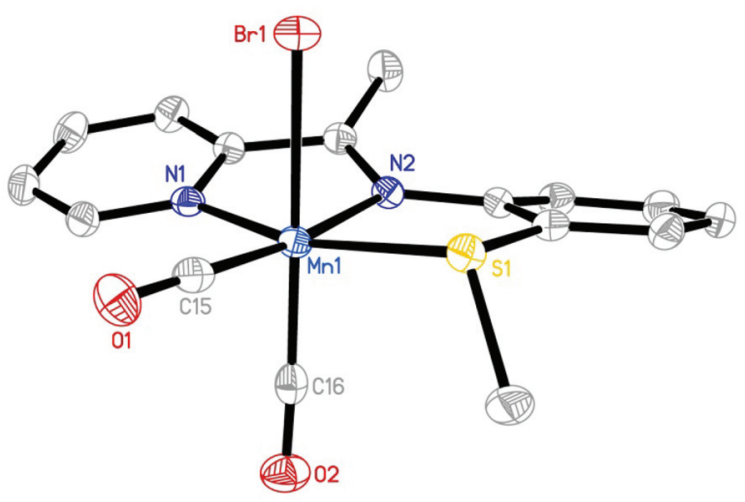

Fig. 3 ORTEP diagram (50\% ellipsoids) of the molecular structure of $\left[\left(\mathrm{N}_{\mathrm{Me}} \mathrm{NS}\right) \mathrm{Mn}(\mathrm{CO})_{2} \mathrm{Br}\right] . \mathrm{H}$ atoms are omitted for clarity.

Interestingly, binding of the thioether-S induces a twist in the conjugated ligand frame, exhibiting a dihedral angle of $32.06^{\circ}$ from the Schiff base to the aryl(thioether) moiety. In $\mathbf{4}_{\mathbf{C O}}$, the origin of thioether ligation is likely steric: in $\mathbf{1}_{\mathbf{C O}}$, the distance from the unbound and 'twisted' aryl-S- $\mathrm{CH}_{3}$ to the imine- $\mathrm{H}$ is $\sim 3.0$ A. In the case of $\mathbf{4}_{\mathbf{C O}}$, replacement of the imine-H with imine- $\mathrm{CH}_{3}$ would decrease this contact to within the van der Waals radii, disallowing protrusion of the thioether in the direction of the Schiff base linkage. Thus, binding of the S-donor and concomitant release of one carbonyl ligand is preferred in $\mathbf{4}_{\mathbf{C O}}$. The two remaining carbonyl ligands are bound in cis fashion $(\mathrm{Mn}-\mathrm{C}(\mathrm{O})=1.789(3), 1.789(3) \AA)$, as is often obligatory in manganese dicarbonyls. The remaining coordination site is occupied by bromide at a distance of 2.5564(7) A.

\section{Spectroscopic characterization}

Infrared spectra. The IR spectrum of $\left[\left({ }_{\mathrm{H}} N N S\right) \mathrm{Mn}(\mathrm{CO})_{3} \mathrm{Br}\right]$ $\left(\mathbf{1}_{\mathbf{C O}}\right)$ is shown in Fig. 4 (bottom red line), wherein the carbonyl stretches at 2023, 1917, and $1867 \mathrm{~cm}^{-1}$ are due to the three chemically distinct carbonyls in the complex. Comparison of this IR with that of the fully ligated dicarbonyl complex $\left[\left(N_{\mathrm{Me}} N S\right) \mathrm{Mn}(\mathrm{CO})_{2} \mathrm{Br}\right]\left(\mathbf{4}_{\mathrm{CO}}\right)$ allows identification of the highest energy (and lowest intensity) peak at $2023 \mathrm{~cm}^{-1}$ in $\mathbf{1}_{\mathbf{C O}}$ as the $\mathrm{CO}$ ligand trans from the $\mathrm{N}_{\mathrm{py}}$ donor (absent in $\mathbf{4}_{\mathbf{C O}}$ ). The high energy of this stretch is presumably due to the strong $\pi$-acceptor capacity of the pyridine moiety. In the same vein, we assign the lowest energy $\nu(\mathrm{CO})$ stretches $\left(1867 \mathrm{~cm}^{-1}\right.$ in $\mathbf{1}_{\mathbf{C O}}$; $1847 \mathrm{~cm}^{-1}$ in $\mathbf{4}_{\mathbf{C O}}$ ) as the carbonyl ligand trans from the $\mathrm{Br}^{-}$ donor, due to its greater $\pi$-donor strength (greater $\pi^{*}(\mathrm{CO})$ electron density). The remaining $\nu(\mathrm{CO})$ stretches are of nearly identical value (1917 cm $\mathrm{cm}^{-1}, \mathbf{1}_{\mathbf{C O}} ; 1918 \mathrm{~cm}^{-1}, \mathbf{4}_{\mathbf{C O}} ; 1918 \mathrm{~cm}^{-1}, \mathbf{5}_{\mathbf{C O}}$ ), owing to their analogous chemical environment trans from the $\mathrm{N}_{\mathrm{SB}}$ donor. The other tricarbonyls $\left(\mathbf{2}_{\mathbf{C O}}, \mathbf{3}_{\mathbf{C O}}\right)$ follow the same trend. The IR spectrum of the 2-methylpyridine species $\mathbf{3}_{\mathbf{C O}}$ is shown at the bottom of Fig. 4. Although it is a tricarbonyl like $\mathbf{1}_{\mathbf{C O}}$, the spectrum of $\mathbf{3}_{\mathrm{CO}}$ does not exhibit three distinct $\nu(\mathrm{CO})$ bands. Rather, the two lower energy stretches (assigned as trans to $\mathrm{Br}$, and trans to $\mathrm{N}_{\mathrm{SB}}$ ) appear largely merged near $1925 \mathrm{~cm}^{-1}$. The steric (or agostic) perturbation of the CO ligands' environment(s) by the ortho methyl group may be

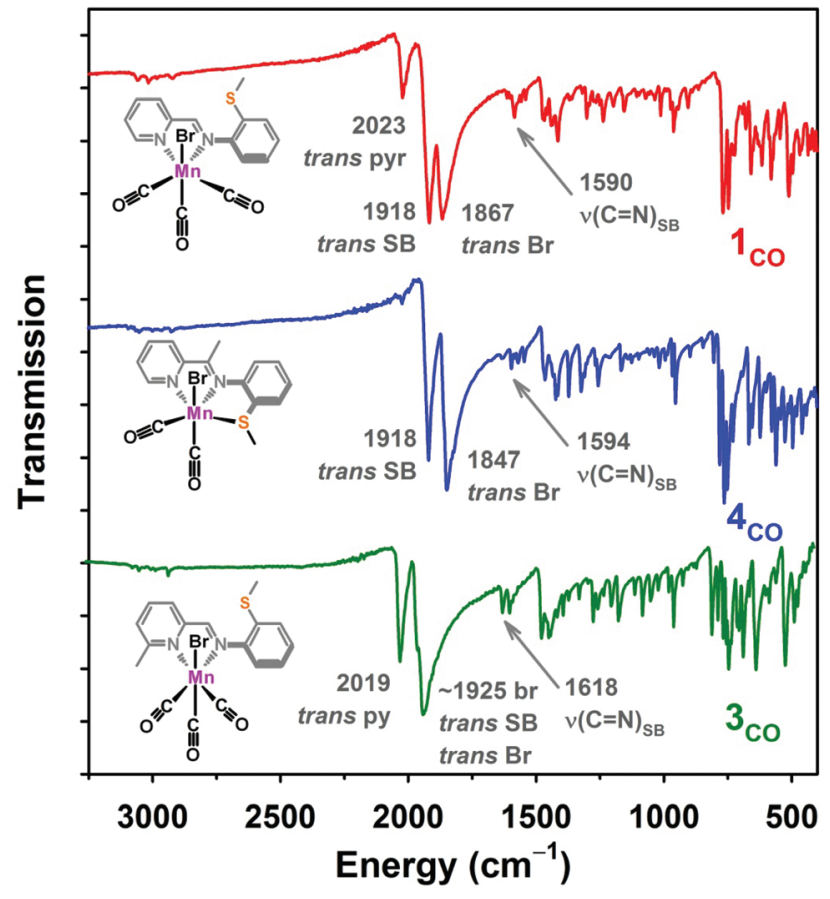

Fig. 4 Infrared spectra of $\left[\left({ }_{\mathrm{H}} N N \mathrm{NS}\right) \mathrm{Mn}(\mathrm{CO})_{3} \mathrm{Br}\right]\left(1_{\mathrm{CO}}\right.$, top red line), $\left[\left(\mathrm{N}_{\mathrm{Me}} \mathrm{NS}\right) \mathrm{Mn}(\mathrm{CO})_{2} \mathrm{Br}\right]\left(4_{\mathrm{CO}}\right.$, middle blue line) and $\left[(\mathrm{Me} N \mathrm{NS}) \mathrm{Mn}(\mathrm{CO})_{3} \mathrm{Br}\right]$ ( $3 \mathrm{co}$, bottom green line) at $298 \mathrm{~K}$ in the solid state.

apparent. Overall, due to the varying coordination geometries, we unambiguously assigned each $\mathrm{CO}$ stretch. Future complexes could be structurally assigned on this basis (IR) in the absence of X-ray structural characterization.

${ }^{\mathbf{1}} \mathbf{H}$ NMR spectra of $\mathbf{1}_{\mathbf{C O}}, \mathbf{3}_{\mathbf{C O}}$ and $\mathbf{4}_{\mathbf{C O}}$. This set of complexes represents all of the structural motifs found in the X-ray structures that are reported in this work. The properties of several complexes in $\mathrm{CD}_{2} \mathrm{Cl}_{2}$ solution were investigated with regard to the bound/unbound thioether unit. We found that two complexes $\left(\mathbf{1}_{\mathbf{C O}}, \mathbf{3}_{\mathbf{C O}}\right)$ exhibited ${ }^{1} \mathrm{H}$ NMR spectra consistent with a single species in solution (according to their X-ray structure), whereas one complex $\left(\mathbf{4}_{\mathbf{C O}}\right)$ exhibited two species in solution. Below we discuss the straightforward cases of $\mathbf{1}_{\mathbf{C O}}$ and $\mathbf{3}_{\mathbf{C O}}$, followed by a comparative interpretation of the more complex phenomena observed for $\mathbf{4}_{\mathbf{C O}}$.

The ${ }^{1} \mathrm{H}$ NMR spectrum of $\mathbf{1}_{\mathbf{C O}}$ in $\mathrm{CD}_{2} \mathrm{Cl}_{2}$ at room temperature is shown in Fig. 5. The broadness of the peaks and lack of observed multiplicities were not resolved by lower temperature spectra (see ESI, Fig. S1†). Nonetheless, the spectrum indicates the presence of a single species in solution, and the unbound state of the thioether-S is indicated by the nearly unchanged value of the $\mathrm{S}-\mathrm{CH}_{3}$ peak in the complex (2.54 ppm) versus that of the free NNS ligand (2.48 ppm). The furthest downfield peaks are indicative of the imino $\mathrm{N}=\mathrm{C}(H)(9.27 \mathrm{ppm})$ in $\mathbf{1}_{\mathbf{C O}}$, which is shifted significantly downfield from the free ligand $\left(\delta_{\text {free }}=8.57 \mathrm{ppm}\right)$. This claim is supported by the spectrum of the iminomethyl complex $\mathbf{4}_{\mathbf{C O}}$ (vide infra), which exhibits no Schiff base $H$ (singlet) in the 8.5-9.5 ppm region. The $\mathrm{C}-H$ at the ortho position of the bound pyridine experiences a smaller 

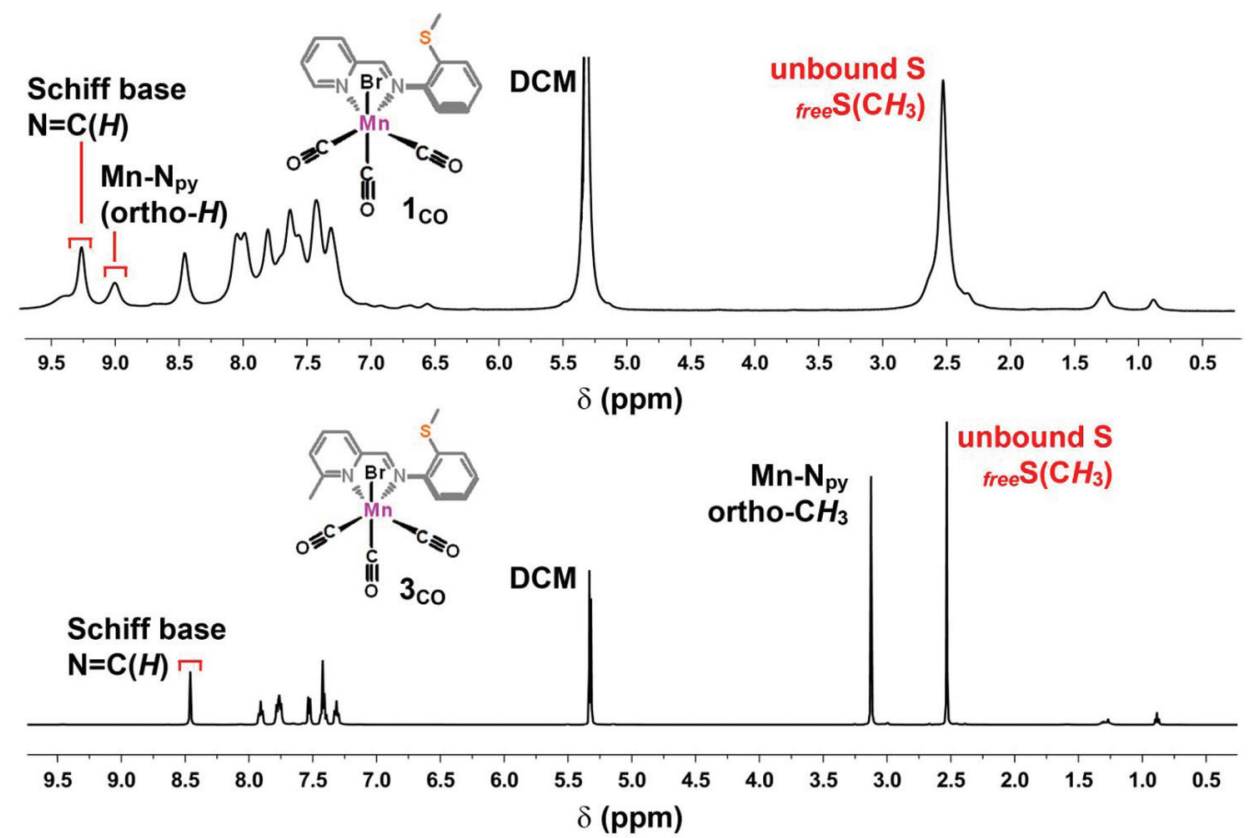

Fig. $5{ }^{1} \mathrm{H}$ NMR spectra $(500 \mathrm{MHz})$ of $\left[(\mathrm{NNS}) \mathrm{Mn}(\mathrm{CO})_{3} \mathrm{Br}\right]\left(1_{\mathrm{CO}}\right.$, top panel) and $\left[\left(\mathrm{Me}_{\mathrm{NNS}}\right) \mathrm{Mn}(\mathrm{CO})_{3} \mathrm{Br}\right]\left(3_{\mathrm{CO}}\right.$, bottom panel) in $\mathrm{CD}_{2} \mathrm{Cl}{ }_{2}$ at $25^{\circ} \mathrm{C}$.

downfield shift upon metal binding $\left(\delta_{\text {bound }}=8.99 \mathrm{ppm} ; \delta_{\text {free }}=\right.$ 8.70). This claim is supported by the spectrum of the orthomethylpyridine complex $\mathbf{3}_{\mathbf{C O}}$ (vide infra), which exhibits no ortho $H_{\text {py }}$ (doublet) peak near between $\sim 8.5$ and $9.0 \mathrm{ppm}$.

The ${ }^{1} \mathrm{H}$ NMR spectra of $\left[\left(\mathrm{Me}^{N N S}\right) \mathrm{Mn}(\mathrm{CO})_{3} \mathrm{Br}\right]\left(\mathbf{3}_{\mathrm{CO}}\right)$ in $\mathrm{CD}_{2} \mathrm{Cl}_{2}$ is shown at the bottom of Fig. 5. This complex exhibits a much sharper spectrum, and is broadened by VT experiments at lower temperature (ESI, Fig. S2 $\dagger$ ). This complex exhibits a $\mathrm{N}=\mathrm{C}(H)$ resonance at $8.46 \mathrm{ppm}$, which is quite similar compared to the free ${ }_{\mathrm{Me}} \mathrm{NNS}$ ligand ( $\delta_{\text {free }}=8.55 \mathrm{ppm}$ ). In the alkyl region, the complex exhibits two resonances (each $3 \mathrm{H}$, singlet) corresponding to the $\mathrm{S}-\mathrm{CH}_{3}$ and $o-\mathrm{CH}_{3}$ (py) units. These peaks are not readily assigned in the spectrum of the free ligand $(2.63,2.47 \mathrm{ppm} ; 3 \mathrm{H}$, singlets) due to their close proximity. As the pyridine unit is bound to the $\mathrm{Mn}$ center in all structurally characterized complexes, we ascribe the downfield-shifted resonance at $3.13 \mathrm{ppm}$ to the Mn-bound ortho $\mathrm{CH}_{3}$ (py) unit. We do not ascribe this resonance to the $\mathrm{S}-\mathrm{CH}_{3}$ unit (instead ascribed to the feature at $2.53 \mathrm{ppm}$ ), as only a Mn-bound thioether unit would exhibit a feature near $\sim 3$ ppm (vide infra). The X-ray structure of $\mathbf{3}_{\mathbf{C O}}$ (Fig. 2) also strongly argues against thioether-S binding in solution (crystallized from $\mathrm{CH}_{2} \mathrm{Cl}_{2}$, NMR studies performed in $\mathrm{CD}_{2} \mathrm{Cl}_{2}$ ). In contrast, we do present evidence of thioether-S binding in the case of $\mathbf{4}_{\mathbf{C O}}$ (vide infra), which does exhibit a Mn-bound thioether unit in the X-ray structure.

The ${ }^{1} \mathrm{H}$ NMR spectra of $\left[\left(\mathrm{N}_{\mathrm{Me}} \mathrm{NS}\right) \mathrm{Mn}(\mathrm{CO})_{2} \mathrm{Br}\right]\left(\mathbf{4}_{\mathrm{CO}}\right)$ is shown in Fig. 6 . The room temperature spectrum of $\mathbf{4}_{\mathbf{C O}}$ (top) exhibits broad peaks devoid of observable multiplicities. The resonance peaks become somewhat sharper upon decreasing the temperature from RT $\rightarrow-40{ }^{\circ} \mathrm{C}$. However, no changes in the number of peaks nor chemical shifts are observed. Below
$-40{ }^{\circ} \mathrm{C}$ (not shown), the peaks revert to broader linewidths due to the limited solubility of $\mathbf{4}_{\mathbf{C O}}$ in $\mathrm{CD}_{2} \mathrm{Cl}_{2}$. As envisaged from the X-ray structure of $\mathbf{4}_{\mathbf{C O}}$ (thioether-S bound), the complex should exhibit two resonances in the alkyl region, emanating from (i) the $\mathrm{N}=\mathrm{C}\left(\mathrm{CH}_{3}\right)$ unit (2.34 ppm in the free ligand), and (ii) the thioether moiety $\left(\delta_{\text {free }}=2.43 \mathrm{ppm}\right)$; however, four peaks are observed in this region. Similarly, a set of eight resonances are expected in the aromatic region, but a more complicated set of $>10$ peaks is observed. One readily identifiable aromatic feature(s) should be the ortho- $H$ of the bound pyridine, observed near $\sim 9 \mathrm{ppm}$. Two broad peaks are observed in this region $(9.29,8.98 \mathrm{ppm})$ in a $1.3: 1$ ratio. This suggested that two species were present in solutions of $\mathbf{4}_{\mathbf{C O}}$ in $\mathrm{CD}_{2} \mathrm{Cl}_{2}$.

Overall, integration of the spectrum of $\mathbf{4}_{\mathrm{CO}}$ at $-20{ }^{\circ} \mathrm{C}$ (optimum resolution) reveals that the two distinct sets of peaks are present in a roughly $1.3: 1$ ratio; the ratio is temperature independent in the accessible range ( $\mathrm{RT} \rightarrow-40^{\circ} \mathrm{C}$ ). In the alkyl region, the furthest downfield methyl resonance at $3.01 \mathrm{ppm}$ is significantly different than the furthest downfield resonance in the free ligand $(2.43 \mathrm{ppm})$. Based on the X-ray structure of $\mathbf{4}_{\mathbf{C O}}$ that exhibits a Mn-bound thioether-S, we assign the peak at $3.01 \mathrm{ppm}$ as the $\mathrm{Mn}$-bound $\mathrm{S}-\mathrm{CH}_{3}$ unit. By integration, the corresponding Schiff base $(\mathrm{N}=\mathrm{C}) \mathrm{CH}_{3}$ unit is observed at $2.47 \mathrm{ppm}$. The furthest upfield peak in the spectrum of $\mathbf{4}_{\mathbf{C O}}(2.39 \mathrm{ppm})$ is quite similar to the Schiff base methyl peak in the free ligand (2.34 ppm), and we assign it as the $(\mathrm{N}=\mathrm{C}) \mathrm{CH}_{3}$ unit in a second species. As the one remaining alkyl resonance at $2.54 \mathrm{ppm}$ is quite similar to that of the unbound thioether in the free ligand (2.43), we assign it as belonging to this second species in solution in which the thioether-S is unbound. Based on integration values, we assign the peak at 8.98 to the S-bound ( $\mathrm{S}$ trans to py) species and the 


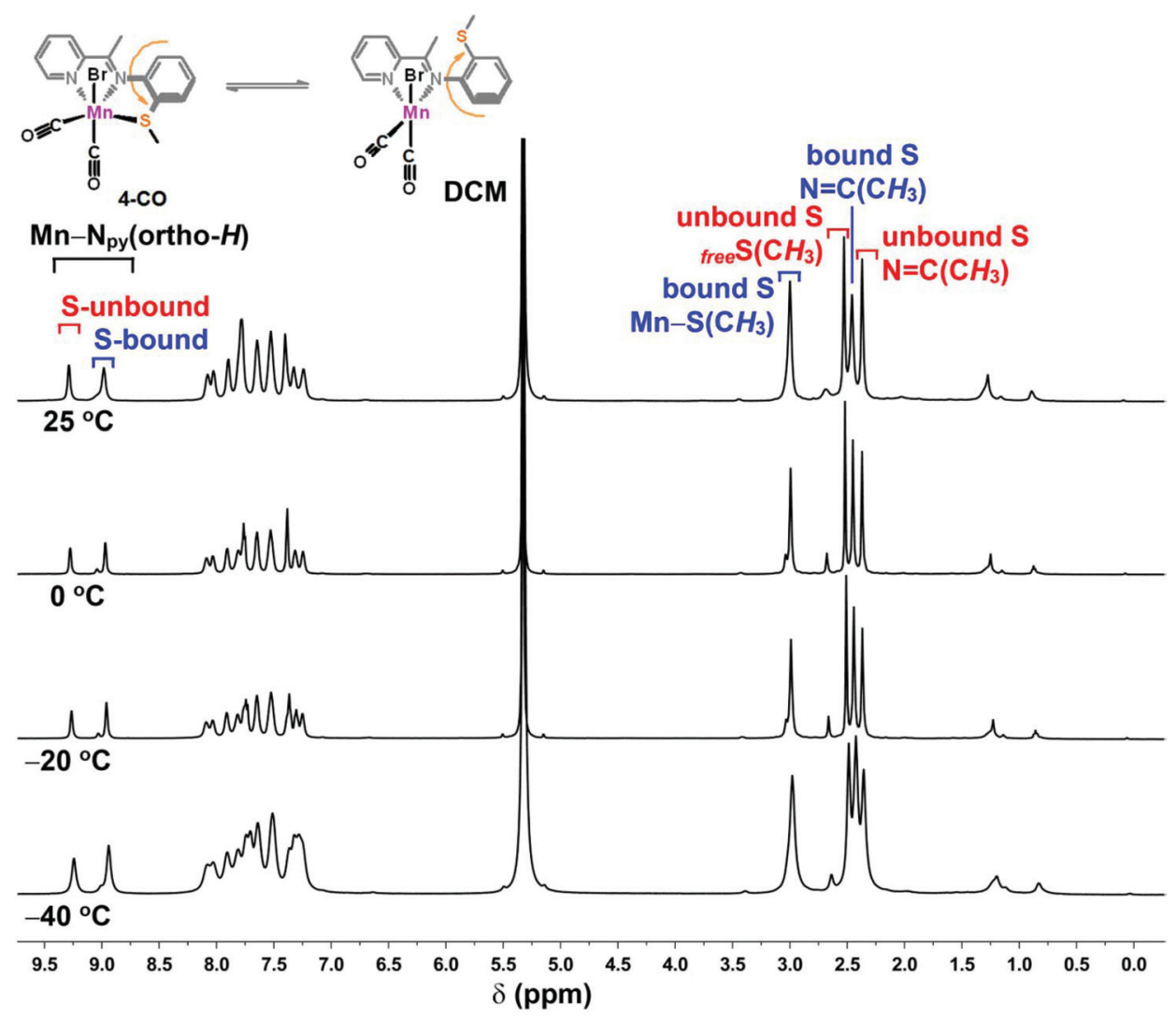

Fig. 6 Variable temperature ${ }^{1} \mathrm{H}$ NMR spectra $(500 \mathrm{MHz})$ of solution species derived from dissolving crystals of $\left.\left[\left(\mathrm{N}_{\mathrm{Me}} \mathrm{NS}\right) \mathrm{Mn}_{(\mathrm{CO})}\right)_{2} \mathrm{Br}\right]\left(4_{\mathrm{CO}}\right)$ in $\mathrm{CD}{ }_{2} \mathrm{Cl}{ }_{2}$.

9.29 feature to the S-unbound species (CO trans to py). Due to lack of observable multiplicities, the assignment of the remaining aromatic peaks remains ambiguous.

We hypothesized that the second species in solution (i.e. "S-unbound", not crystallographically characterized) was the five-coordinate species as shown in scheme 3. To our knowledge, there are three authentic precedents (i.e. no redox active ligand) regarding the isolation and X-ray structural characterization of five-coordinate $\mathrm{Mn}(\mathrm{I})$ carbonyls; all are deep blue, diamagnetic species supported by P4 phosphine donor sets $(2 \times$ dppe, depe, etc. $)$ in rigid square pyramidal orientation. ${ }^{34-36}$ The ${ }^{1} \mathrm{H}$ NMR experiments described above ( 10-100 mM concentrations) indicated that the relative proportions of the two populations were not affected by temperature (RT $\rightarrow-40^{\circ} \mathrm{C}$ ). However, in the course of performing
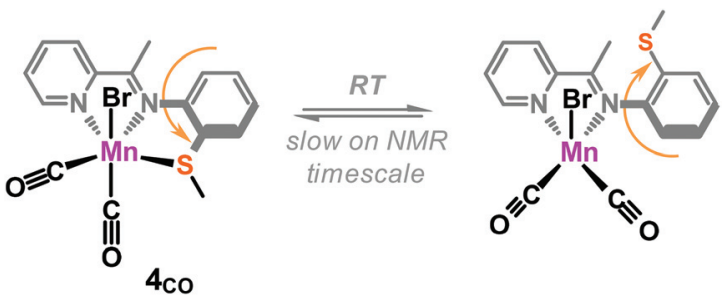

Scheme 3 Speciation observed between diamagnetic 6- and 5-coordinate species as observed in the case of $4 \mathrm{CO}$ in ${ }^{1} \mathrm{H}$ NMR experiments in $\mathrm{CD}_{2} \mathrm{Cl}_{2}$. routine, analytical UV/vis measurements, we noted a drastic change in color upon dilution of red solutions of $\mathbf{4}_{\mathrm{CO}}$ to a blue/violet color. This indicated a possible change in relative proportions of species (5- and 6-coordinate) as a function of concentration.

The fact that the peaks do not coalesce at any tested temperature indicates that the kinetics of the equilibrium do not occur on the NMR timescale. This is not surprising in light of the low-spin, $d^{6}$ kinetically inert configuration of the pseudooctahedral manganese center, which would prevent rapid interconversion between conformers. The octahedral ligand field splitting would be amplified by the $t_{2 g}$ type interactions among the metal-carbonyl $\left\{d_{\mathrm{p}}(\mathrm{Mn})-\pi^{*}(\mathrm{CO})\right\}$ bonding units. Thus, there are two distinct, kinetically stable populations of species during the NMR experiment in $\mathrm{CD}_{2} \mathrm{Cl}_{2}$. The reason(s) for the preferential crystallization of the S-bound conformer from $\mathrm{CH}_{2} \mathrm{Cl}_{2}$ in the synthetic procedure is not clear at this time.

The observed broadness of the peaks in $\mathbf{1}_{\mathrm{CO}}$ and $\mathbf{4}_{\mathrm{CO}}$ is most likely due to the conformational flexibility of the unbound aryl-thioether unit. While the broad linewidths in the case of $\mathbf{4}_{\mathrm{CO}}$ may be related to the slow interconversion of the two species (S-bound and S-unbound), the reason for the peak broadness in $\mathbf{1}_{\mathrm{CO}}$ remains unclear. As a corollary, the reason for the structural rigidity in the case of $\mathbf{3}_{\mathbf{C O}}$ (viz. a vis sharp ${ }^{1} \mathrm{H}$ NMR spectra) also is not clear. It is possible that the ortho $\mathrm{CH}_{3}$ (py) unit serves as a structural "anchor" that fixes 

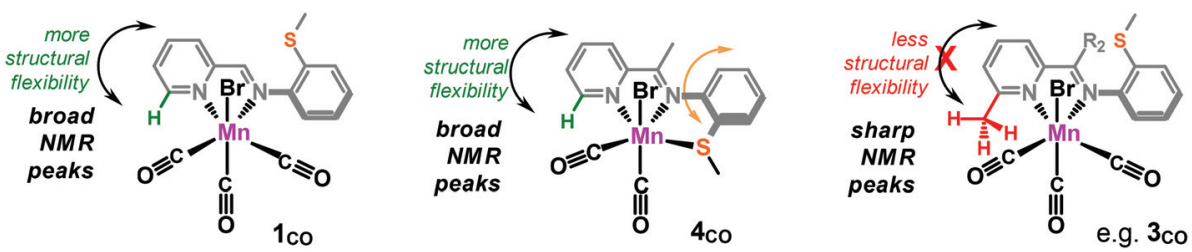

Scheme 4 Schematic representation regarding the observed broad linewidths of $1_{\mathrm{CO}}$ and $4_{\mathrm{CO}}$ (but not $3_{\mathrm{CO}}$ ) in ${ }^{1} \mathrm{H} \mathrm{NMR}$ experiments in $\mathrm{CD}_{2} \mathrm{Cl}_{2}$.

the ligand framework in position via an agostic interaction with the CO ligand trans to the $\mathrm{N}_{\mathrm{SB}}$ donor. The interaction of the 2-methylpyridine moiety with the carbonyl ligand (i.e. $\left.{ }_{\text {py }} \mathrm{CH}_{3} \cdots \mathrm{C} \equiv \mathrm{O}\right)$ may account for the anomalously large downfield shift $(\sim 0.5 \mathrm{ppm})$ observed for the ortho $\mathrm{CH}_{3}$ (py) unit, which is 2 atoms away from the metal binding site. Note that by comparison, the Schiff base methyl unit (also 2 atoms away from the metal binding $\mathrm{N}$ ) exhibits an almost immeasurable shift $(\sim 0.1 \mathrm{ppm})$ upon ligation. As a third case in point, we observe that the ortho- $\mathrm{CH}_{3}$ bearing $\mathbf{3}_{\mathrm{Co}}$ exhibits unusually low solubility in $\mathrm{CH}_{2} \mathrm{Cl}_{2}$ solution as compared to all other complexes - even the unsubstituted $\mathbf{1}_{\mathbf{C O}}$, which would be expected to exhibit the lowest solubility. And although this might be an anecdotal coincidence, it may instead be related to its relative rigidity (or lack of conformational motion) in solution. Preliminary DFT calculations, however, did not reveal any orbital overlap or shared MO density between the ortho $\mathrm{CH}_{3}$ (py) unit and the carbonyl ligand (Scheme 4).

\section{S-bound and -unbound conformers derived from ${ }_{\mathrm{FPh}} \mathrm{NNS}$}

Lastly, we wished to determine the effect of a much larger substituent at the pyridine ortho position. Under identical reaction conditions, metalation of the fluorophenyl derived ligand ${ }_{\mathrm{FPh}} \mathrm{NNS}$ has led to structural characterization of both conformers (S bound/unbound). Fig. 7 below shows conclusively that the fluorophenyl ligand can support both binding modes. Red crystals (blocks) of the tricarbonyl complex $\mathbf{5}_{\mathbf{C O} \text {-a }}$ (S unbound) were obtained by fast vapor diffusion of pentane ( $12 \mathrm{~h}$ to $1 \mathrm{~d})$ into the reaction mixture in $\mathrm{CH}_{2} \mathrm{Cl}_{2}$. Alternatively, crystallization of the same reaction mixture via slow vapor diffusion of $\mathrm{Et}_{2} \mathrm{O}$ ( 2 to 3 days) afforded crystals of $\mathbf{5}_{\mathbf{C O}-\mathbf{b}}$ (black needles, $\mathrm{S}$ bound). The ${ }^{1} \mathrm{H}$ NMR spectrum of $\mathbf{5}_{\mathbf{C O} \text {-a }}$ reveals a single species in solution over the course of one experiment (minutes to 1-2 hours).
The structural parameters of $\mathbf{5}_{\text {CO-a }}$ versus $\mathbf{5}_{\text {Co-b }}$ warrant several comments. In the S-unbound state $\mathbf{5}_{\mathbf{C O}-\mathbf{a}}$, the fluorophenyl unit is quite close to the proximal carbonyl: the ipso carbon (C14) is located at a distance of $\sim 2.95 \AA$ from the carbonyl (C20). This same carbonyl unit exhibits the longest Mn$\mathrm{C}(\mathrm{O})$ distance $(1.824(2) \AA)$ of all of the complexes reported here, likely due to the close proximity of the fluorophenyl unit. The $\mathrm{FPh}$ unit is also twisted out of the conjugated plane by $62.1^{\circ}$, and even more strikingly it diverges $8^{\circ}$ from the expected linear alignment across the $\mathrm{C}_{\mathrm{py}}-\mathrm{C}_{i p s o}-\mathrm{C}_{\mathrm{F}}$ axis. In contrast, the S-bound conformer $\mathbf{5}_{\mathbf{C O}-\mathbf{b}}$ exhibits a more 'relaxed' orientation of the fluorophenyl unit. The $\mathrm{C}_{i p s o} \cdots \mathrm{C}(\mathrm{O})$ distance is elongated to $3.097 \AA$, and the phenyl unit (although still twisted $62.8^{\circ}$ out of the conjugated plane), adopts a more conventional, linear orientation along the $\mathrm{C}_{\mathrm{py}}-\mathrm{C}_{i p s o}-\mathrm{C}_{\mathrm{F}}$ axis $\left(178.85^{\circ}\right)$. The IR spectra of the complexes is also consistent with these findings. Complex $\mathbf{5}_{\mathbf{C O}-\mathbf{a}}$ (the tricarbonyl) exhibits three $\mathrm{CO}$ stretches at 2021, 1943 and $1914 \mathrm{~cm}^{-1}$, while $\mathbf{5}_{\mathbf{C O}-\mathbf{b}}$ (dicarbonyl) exhibits two CO stretches at 1934 and $1872 \mathrm{~cm}^{-1}$. These are also consistent with the $\nu(\mathrm{CO})$ values for $\mathbf{1}_{\mathbf{C O}}$ and $\mathbf{4}_{\mathbf{C O}}$ depicted in Fig. 4 (Scheme 5).

\section{Electronic absorption spectra}

In making routine UV/vis measurements, we noticed blue or violet colors observed in dilute solutions of several of the complexes - namely $\mathbf{2}_{\mathbf{C O}}, \mathbf{4}_{\mathbf{C O}}$ and $\mathbf{5}_{\mathbf{C O}-\mathbf{b}}\left(\lambda_{\mathrm{abs}}=611,560\right.$, $612 \mathrm{~nm}$ respectively); the dicarbonyls $\mathbf{4}_{\mathbf{C O}}$ and $\mathbf{5}_{\mathbf{C O}-\mathbf{b}}$ crystallized as black crystals, which upon crushing in $\mathrm{KBr}$ afforded grayishviolet powders. [Note that $\mathbf{4}_{\mathrm{CO}}$ showed multiple species in ${ }^{1} \mathrm{H}$ NMR experiments.] In contrast, species exhibiting orange to red solutions were correlated with complexes that exhibited a single set of peaks in the ${ }^{1} \mathrm{H}$ NMR spectrum $\left(\mathbf{1}_{\mathbf{C O}}, \mathbf{3}_{\mathbf{C O}}\right)$. Table 3 summarizes the collected UV/vis data.
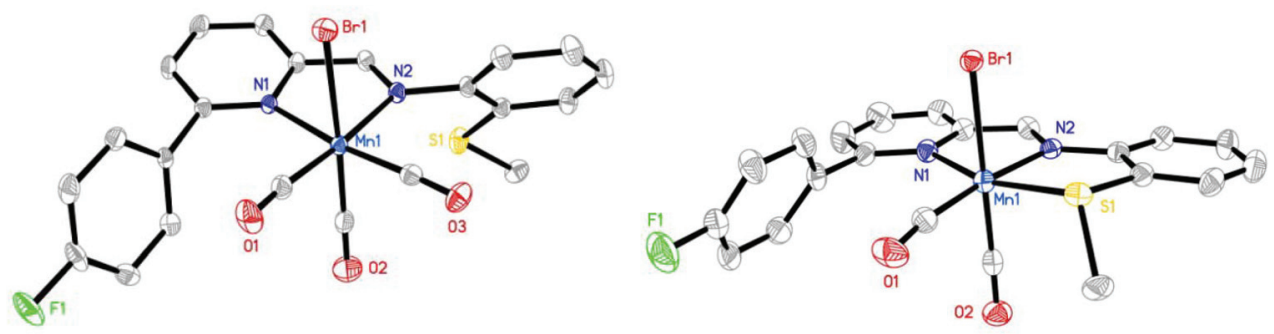

Fig. 7 ORTEP diagrams (50\% ellipsoids) of the structural conformers of the ${ }_{\mathrm{FPh}} \mathrm{NNS}$ ligand: [( $\left.\mathrm{FPh}_{\mathrm{NNS}} \mathrm{Mn}(\mathrm{CO})_{3} \mathrm{Br}\right]\left(5_{\mathrm{CO}-\mathrm{a}}\right.$ left) and [( $\left.\mathrm{FPh} N N S\right) \mathrm{Mn}-$ $\left.(\mathrm{CO})_{2} \mathrm{Br}\right]\left(5_{\mathrm{CO}-\mathrm{b}}\right.$, right). For a description of the full disorder model found for $5_{\mathrm{CO}-\mathrm{b}}$, see X-ray section in Experimental and ESI (Fig. S2 $\dagger$ ). 


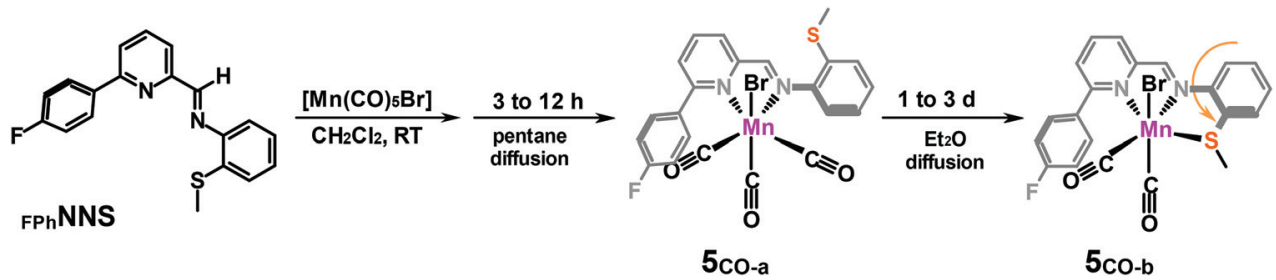

Scheme 5 Preparation and sequential isolation of $\left[\left({ }_{\mathrm{FPh}} N N S\right) \mathrm{Mn}(\mathrm{CO})_{3} \mathrm{Br}\right]\left(5_{\mathrm{CO}-\mathrm{a}}\right)$ and $\left[\left(\mathrm{FPh}_{\mathrm{N}} \mathrm{NNS}\right) \mathrm{Mn}(\mathrm{CO})_{2} \mathrm{Br}\right]\left(5_{\mathrm{CO}-\mathrm{b}}\right)$.

Table $3 \mathrm{UV} / \mathrm{vis}$ data (wavelengths in $\mathrm{nm}, \varepsilon$-values in $\mathrm{M}^{-1} \mathrm{~cm}^{-1}$ ) of manganese carbonyls determined in dry $\mathrm{CH}_{2} \mathrm{Cl}_{2}$ under argon atmosphere $(298 \mathrm{~K})$

\begin{tabular}{|c|c|c|c|}
\hline Complex & Color & $\begin{array}{l}\lambda_{1} \text { in } \mathrm{nm} \\
\left(\varepsilon \text { in } \mathrm{M}^{-1} \mathrm{~cm}^{-1}\right)\end{array}$ & $\begin{array}{l}\lambda_{2} \text { in } \mathrm{nm} \\
\left(\varepsilon \text { in } \mathrm{M}^{-1} \mathrm{~cm}^{-1}\right)\end{array}$ \\
\hline $\mathbf{1}_{\mathrm{CO}}\left[(\mathrm{NNS}) \mathrm{Mn}(\mathrm{CO})_{3} \mathrm{Br}\right]$ & Orange & $323(20000)$ & - \\
\hline $2_{\mathrm{CO}}\left[\left(\mathrm{ome}^{N N S}\right) \mathrm{Mn}(\mathrm{CO})_{3} \mathrm{Br}\right]$ & Blue & $354(4000)$ & $611(4000)$ \\
\hline $\mathbf{3}_{\mathrm{CO}}\left[(\mathrm{Me} N N \mathrm{~S}) \mathrm{Mn}(\mathrm{CO})_{3} \mathrm{Br}\right]$ & Yellow & $314(7490)$ & $488(1570)$ \\
\hline $\mathbf{4}_{\mathrm{CO}}\left[\left(N_{\mathrm{Me}} N S\right) \mathrm{Mn}(\mathrm{CO})_{2} \mathrm{Br}\right]$ & Violet & $319(7450)$ & $560(800)$ \\
\hline $\mathbf{5}_{\mathrm{COa}}\left[(\mathrm{FPh} N N \mathrm{Mn}) \mathrm{Mn}(\mathrm{CO})_{3} \mathrm{Br}\right]$ & Red & $325(6300)$ & $497(1120)$ \\
\hline $\mathbf{5}_{\mathrm{COb}}\left[(\mathrm{FPh} N N S) \mathrm{Mn}(\mathrm{CO})_{2} \mathrm{Br}\right]$ & Teal & $332(3250)$ & $612(500)$ \\
\hline
\end{tabular}

We hypothesize that the blue species observed with $\mathbf{4}_{\mathbf{C O}}$ in $\mathrm{CH}_{2} \mathrm{Cl}_{2}$ (where two species were observed in ${ }^{1} \mathrm{H} \mathrm{NMR}$, vide supra) may be the 5-coordinate species in which the thioether$\mathrm{S}$ is unbound. There are several previous reports of 5-coordinate $\mathrm{Mn}(\mathrm{I})$ carbonyls that have been structurally characterized: $\left[\left(\mathrm{PN}_{\mathrm{Me}} \mathrm{P}\right)(\mathrm{dppm}) \mathrm{Mn}(\mathrm{CO})\right]^{+},\left[(\mathrm{dppe})_{2} \mathrm{Mn}(\mathrm{CO})\right]^{+}$and $\left[(\text {depe })_{2} \mathrm{Mn}-\right.$ $(\mathrm{CO})]^{+}{ }^{34-36}$ Each complex was described as "dark blue" or "deep blue" by the reporting authors (no UV/vis data reported), both in solution and in crystalline form. It is possible that the blue species observed in this work under dilute conditions in non-coordinating solvent (dry $\mathrm{CH}_{2} \mathrm{Cl}_{2}$, argon atmosphere) is also such a 5-coordinate species. It also is possible that at higher concentrations, $\mathrm{Mn} \cdots \mathrm{Mn}$ interactions or intermolecular Mn...S(unbound) associations prevent accumulation of sufficient quantities of the 5-coordinate species. We are further investigating the nature of the blue species by more detailed spectroscopies and structural characterization attempts.

\section{Conclusion}

Overall, the sequential fashion of the isolation of $\mathbf{5}_{\mathbf{C O}-\mathbf{a}}$ and $\mathbf{5}_{\mathbf{C O}-\mathbf{b}}$ (and structural characterization of both conformers), as well as ${ }^{1} \mathrm{H}$ NMR and UV/vis measurements allow us to postulate a step-wise scheme to explain all of the results observed herein. Metalation of $\left[\mathrm{Mn}(\mathrm{CO})_{5} \mathrm{Br}\right]$ with NNS-type ligands affords an initial product wherein the ligand is bound in NNS fashion ( $\mathrm{S}$ unbound). Depending on the nature of both $\mathrm{R}_{1}$ and $R_{2}$, conversion to the S-bound species can be fast, slow or not observed. In the case of $\mathrm{R}_{1}$, conversion of the tricarbonyl to the dicarbonyl is mildly accelerated by a large change in sterics. A very bulky $\mathrm{R}_{1}$ substituent (i.e. for $\mathrm{R}_{1}=\mathrm{FPh}$, but not
$\mathrm{CH}_{3}$ or $\mathrm{OCH}_{3}$ ) induces a 'puckering' of the bound NNS fragment; this tension is released upon binding of the sulfur in the dicarbonyl. For $\mathrm{R}_{2}$ (Schiff base substituent), conversion of the tricarbonyl to the dicarbonyl is accelerated by even a small steric change $\left(\mathrm{R}_{2}=\mathrm{H} \rightarrow \mathrm{CH}_{3}\right)$, due to steric repulsion of the $\mathrm{S}-\mathrm{CH}_{3}$ unit with $\mathrm{N}=\mathrm{C}\left(\mathrm{CH}_{3}\right)$ in the unbound state. This results in several examples of a $\left\{\mathrm{Mn}(\mathrm{CO})_{2}\right\}^{+}$fragment supported by a neutral, thioether-containing ligand.

\section{Summary}

We summarize our findings in the following points:

(a) Consistent with others' findings, thioether-S donors are generally not favorable donors in manganese(I) carbonyl systems.

(b) Substitution of an iminomethyl moiety can enforce binding of the thioether-S, likely due to unfavorable steric interactions in the unbound conformation of the ligand.

(c) In the iminomethyl ligand $\left(\mathrm{N}_{\mathrm{Me}} \mathrm{NS}\right),{ }^{1} \mathrm{H}$ NMR studies reveal an equilibrium of the 6 -coordinate ( $\mathrm{S}$ bound) and a second [possibly 5 -coordinate (S unbound)] species. The ${ }^{1} \mathrm{H}$ NMR spectra of the aldehyde-derived NNS complexes reveal a single conformer - the S-unbound species.

(d) A significant electronic and steric substitution at the pyridine ortho position (fluorophenyl) leads to isolation of both S-bound and S-unbound species with resolution provided by kinetics (12 h versus 3 days crystallization time) and/or choice of crystallization solvent (pentane $v s$. $\mathrm{Et}_{2} \mathrm{O}$ ).

(e) We provide several new examples of the $\left\{\mathrm{Mn}(\mathrm{CO})_{2}\right\}^{+}$fragment stabilized by ${ }_{\mathbf{F P h}} \mathbf{N N S}$ and $\mathbf{N}_{\mathbf{M e}} \mathbf{N S}$; such dicarbonyls are usually stabilized only by phosphine ligands.

(f) A rational design of the ligand framework $\left(R_{1}, R_{2}\right)$ may now lead to the desired NNS coordination motif in manganese carbonyls.

\section{Acknowledgements}

This research was supported by startup funds to MJR provided by the UT Austin College of Natural Sciences, the Welch Foundation (F-1822), the ACS Petroleum Research Fund (53542DN13). SEL was the recipient of an Undergraduate Research Fellowship sponsored by the UT Austin Office of Research. The authors gratefully acknowledge Angela Spangenberg and Steve Sorey for technical assistance in acquiring VT NMR spectra. 
We also thank Dr Vince Lynch for assistance in the collection of X-ray data and refinement of structures.

\section{References}

1 (a) C. Z. Li, E. Widjaja and M. Garland, Organometallics, 2004, 23, 4131-4138; (b) R. D. Adams, K. Brosius and O. S. Kwon, Inorg. Chem. Commun., 2001, 4, 671-673; (c) T. Kondo, Y. Sone, Y. Tsuji and Y. J. Watanabe, Organomet. Chem., 1994, 473, 163-173.

2 (a) S. Khabuanchalad, J. Wittayakun, R. J. Lobo-Lapidus, S. Stoll, R. D. Britt and B. C. Gates, Langmuir, 2013, 29, 6279-6286; (b) R. Villaneau, A. Proust, F. Robert and P. Gouzerth, Chem. - Eur. J., 2003, 9, 1982-1990.

3 (a) G. Dordelmann, H. Pfeiffer, A. Birkner and U. Schatzschneider, Inorg. Chem., 2011, 50, 4362-4367; (b) N. E. Brueckmann, M. Wahl, G. J. Reiss, M. Kohns, W. Watjen and P. C. Kunz, Eur. J. Inorg. Chem., 2011, 45714577; (c) G. Doerdelmann, T. Meinhardt, T. Sowik, A. Krueger and U. Schatzschneider, Chem. Commun., 2012, 48, 11528-11530; (d) M. A. Gonzalez, N. L. Fry, R. Burt, R. Davda, A. Hobbs and P. K. Mascharak, Inorg. Chem., 2011, 50, 3127-3134; (e) F. Mohr, J. Niesel, U. Schatzschneider and C. W. Lehmann, Z. Anorg. Allg. Chem., 2012, 638, 543-546; (f) R. D. Rimmer, A. E. Pierri and P. C. Ford, Coord. Chem. Rev., 2012, 256, 1509-1519; $(g)$ A. E. Pierri, A. Pallaoro, G. Wu and P. C. Ford, J. Am. Chem. Soc., 2012, 134, 18197-18200; (h) P. C. Ford, Nitric Oxide Biol. Chem., 2013, 34, 56-64.

4 Y. Kuninobu and K. Takai, Bull. Chem. Soc. Jpn., 2012, 85, 656-671.

5 (a) S. K. Russell, A. C. Bowman, E. Lobkovsky, K. Wieghardt and P. J. Chirik, Eur. J. Inorg. Chem., 2012, 535-545, Special Issue $(b)$ F. Hartl, P. Rosa, L. Ricard, P. Le Floch and S. Zalis, Coord. Chem. Rev., 2007, 251, 557-576; (c) F. Hartl and T. Mahabiersing, Inorg. Chem., 2003, 42, 4442-4455; (d) W.-F. Liaw, C.-K. Hsieh, G.-Y. Lin and G.-H. Lee, Inorg. Chem., 2001, 40, 3468-3475; (e) C.-M. Lee, G.-Y. Lin, C.-H. Hsieh, C.-H. Hu, G.-H. Lee, S.-M. Peng and W.-F. Liaw, Dalton Trans., 1999, 2393-2398; $(f)$ W.-F. Liaw, C.-M. Lee, G.-H. Lee and S.-M. Peng, Inorg. Chem., 1998, 37, 6396-6398; (g) F. Hartl, Inorg. Chim. Acta, 1998, 268, $1-11$.

6 (a) Z. B. Mao, B. T. Gregg and A. R. Cutler, Organometallics, 1998, 17, 1993-2002; (b) Z. Mao, B. T. Gregg and A. R. Cutler, J. Am. Chem. Soc., 1995, 117, 10139-10140; (c) M. B. Cavanaugh, B. T. Gregg and A. R. Cutler, Organometallics, 1996, 15, 2764-2769; (d) P. K. Hanna, B. T. Gregg and A. R. Cutler, Organometallics, 1991, 10, 31-33.

7 B. T. Gregg and A. R. Cutler, Organometallics, 1994, 13, 1039-1043.

8 (a) M. Bourrez, F. Molton, S. Chardon-Noblat and A. Deronzier, Angew. Chem., Int. Ed., 2011, 50, 9903-9906; (b) J. M. Smieja, M. D. Sampson, K. A. Grice, E. E. Benson,
J. D. Froehlich and C. P. Kubiak, Inorg. Chem., 2013, 52, 2484-2491.

9 (a) V. S. Thoi, Y. J. Sun, J. R. Long and C. J. Chang, Chem. Soc. Rev., 2013, 42, 2388-2400; (b) J. G. McAlpin, T. A. Stich, W. H. Casey and R. D. Britt, Coord. Chem. Rev., 2012, 256, 2445-2452; (c) S. Fukuzumi, D. C. Hong and Y. J. Yamada, Phys. Chem. Lett., 2013, 4, 3458-3467; (d) R. Brimblecombe, A. Koo, G. C. Dismukes, G. F. Swiegers and L. Spiccia, J. Am. Chem. Soc., 2010, 132, 2892; (e) D. J. Darensbourg and E. B. Frantz, Inorg. Chem., 2007, 46, 5967-5978; (f) D. G. Nocera, Acc. Chem. Res., 2012, 45, 767-776; (g) E. L. Warren, J. R. McKone, H. A. Atwater, H. B. Gray and N. S. Lewis, Energy Environ. Sci., 2012, 5, 96539661.

10 D. Chen, R. Scopelliti and X. Hu, Angew. Chem., Int. Ed., 2012, 51, 1919-1921.

11 D. Chen, R. Scopelliti and X. Hu, Angew. Chem., Int. Ed., 2011, 50, 5671-5673.

12 T. B. Liu, B. Li, C. V. Popescu, A. Bilko, L. M. Perez, M. B. Hall and M. Y. Darensbourg, Chem. - Eur. J., 2010, 16, 3083-3089.

13 B. Li, T. Liu, C. V. Popescu, A. Bilko and M. Y. Darensbourg, Inorg. Chem., 2009, 48, 11283.

14 P. J. Turrell, A. D. Hill, S. K. Ibrahim, J. A. Wright and C. J. Pickett, Dalton Trans., 2013, 42, 8140-8146.

15 S. Kaur-Ghumaan, L. Schwartz, R. Lomoth, M. Stein and S. Ott, Angew. Chem., Int. Ed., 2010, 49, 8033-8036.

16 J. Connolly, A. R. J. Genge, S. D. Orchard, S. J. A. Pope and G. Reid, J. Chem. Soc., Dalton Trans., 1999, 2343-2351.

17 H. Elias, G. Schmidt, H.-J. Küppers, M. Saher, K. Wieghardt, B. Nuber and J. Weiss, Inorg. Chem., 1989, 28, 3021-3024.

18 J. Connolly, G. W. Goodban, G. Reid and A. M. Z. Slawin, J. Chem. Soc., Dalton Trans., 1998, 2225-2231.

19 S.-T. Liu, H.-E. Wang, L.-M. Yin, S.-C. Tsai, K.-J. Liu, Y.-M. Wang, M.-C. Cheng and S.-M. Peng, Organometallics, 1993, 12, 2277-2283.

20 W. Levason, L. P. Ollivere, G. Reid, N. Tsoureas and M. Webster, J. Organomet. Chem., 2009, 694, 2299-2308.

21 B. Patel and G. Reid, Dalton Trans., 2000, 1303-1307.

22 J.-D. Compain, M. Bourrez, M. Haukka, A. Deronzier and S. Chardon-Noblat, Chem. Commun., 2014, 50, 25392542.

23 M. A. Gonzalez, S. J. Carrington, N. L. Fry, J. L. Martinez and P. K. Mascharak, Inorg. Chem., 2012, 51, 1193011940.

24 S. J. Carrington, I. Chakraborty, N. L. Fry, J. L. Martinez and P. K. Mascharak, Chem. Commun., 2013, 49, 1125411256

25 M. A. Gonzalez, M. A. Yim, S. Cheng, A. Moyes, A. J. Hobbs and P. K. Mascharak, Inorg. Chem., 2012, 51, 601-608.

26 B. W. Skelton, V.-A. Tolhurst, A. H. White, A. M. Williams and A. J. Wilson, J. Organomet. Chem., 2003, 674, 38-44.

27 S. K. Chatterjee, S. Roy, S. K. Barman, R. C. Maji, M. M. Olmstead and A. K. Patra, Inorg. Chem., 2012, 51, 7625-7635. 
28 S. Roy, P. Mitra and A. K. Patra, Inorg. Chim. Acta, 2011, 370, 247-253.

29 F. H. Kohler, N. Hebendanz, G. Muller, U. Thewalt, B. Kanellakopulos and R. Klenze, Organometallics, 1987, 6, 115.

30 S. Pohl, W. Saak and P. Z. Stolz, Z. Naturforsch., B: Chem. Sci., 1988, 43, 171.

31 A. N. Chekov, Zh. Neorg. Khim., 2006, 51, 2026.

32 O. Seewald, U. Florke, G. Henkel and T. Seshadri, Acta Crystallogr., Sect. E: Struct. Rep. Online, 2005, 61, m1948.
33 K. Ha, Z. Kristallogr. - New Cryst. Struct., 2011, 226, 518.

34 K. D. Welch, W. G. Dougherty, W. S. Kassel, D. L. DuBois and R. M. Bullock, Organometallics, 2010, 29, 45324540 .

35 W. A. King, B. L. Scott, J. Eckert and G. J. Kubas, Inorg. Chem., 1999, 38, 1069-1084.

36 W. A. King, X.-L. Luo, B. L. Scott, G. J. Kubas and K. W. Zilm, J. Am. Chem. Soc., 1996, 118, 6782-6783. 